\title{
Kinetics and Product Selectivity (Yield) of Second Order Competitive Consecutive Reactions in Fed-Batch Reactor and Plug Flow Reactor
}

\author{
Subash Chandra Bose Selvamony \\ Process Engineering, Arch Pharmalabs Ltd, 541A Marol Maroshi Road, Andheri (East), Mumbai 400059, India \\ Correspondence should be addressed to Subash Chandra Bose Selvamony; ssubashchan@gmail.com
}

Received 27 May 2013; Accepted 19 June 2013

Academic Editors: C. Chen, J. A. A. González, C.-T. Hsieh, and Y. Otsubo

Copyright (C) 2013 Subash Chandra Bose Selvamony. This is an open access article distributed under the Creative Commons Attribution License, which permits unrestricted use, distribution, and reproduction in any medium, provided the original work is properly cited.

\begin{abstract}
This literature compares the performance of second order competitive consecutive reaction in Fed-Batch Reactor with that in continuous Plug Flow Reactor. In a kinetic sense, this simulation study aims to develop a case for continuous Plug Flow Reactor in pharmaceutical, fine chemical, and related other chemical industries. MATLAB is used to find solutions for the differential equations. The simulation results show that, for certain cases of nonelementary scenario, product selectivity is higher in Plug Flow Reactor than Fed-Batch Reactor despite the fact that it is the same in both the reactors for elementary reaction. The effect of temperature and concentration gradients is beyond the scope of this literature.
\end{abstract}

\section{Introduction}

Reactions in pharmaceutical (API-Active Pharmaceutical Ingredients and Drug Intermediates) and fine chemical industries are known for their complexities. Competitive consecutive reactions with intermediate product as the desired product are common in these industries. Many such reactions are conventionally carried out in Fed-Batch (semi-batch) mode, wherein one of the reactants is taken in a batch reactor and the other reactant is added over a period of time $\left(t_{a}\right.$, in second, s) onto the reactant in the reactor, and maintained for a specific period of time, $t_{m}(s)$, till the reaction gets completed. Any choice between the types of reactors, if accompanied by improvement in product yield, will be industrially significant.

\section{The Reaction System}

The following type of reaction system is a representation of second order competitive consecutive reaction:

$$
\mathrm{A}+\mathrm{B} \stackrel{K_{1}}{\longrightarrow} \mathrm{R}+\mathrm{C}, \quad \mathrm{B}+\mathrm{R} \stackrel{K_{2}}{\longrightarrow} \mathrm{S}+\mathrm{D}
$$

$\mathrm{A}, \mathrm{B}, \mathrm{R}, \mathrm{S}, \mathrm{C}$, and $\mathrm{D}$ are various species involved in the reaction.

R-Desired Product; S-Undesired Product. It should be noted that the species mentioned in the representative chemical equation (1) are not the only chemical components present in the reaction system. Most of the times, the reaction system would additionally have one or more solvents.

The general pattern of concentration-time profile of competitive consecutive reaction of the type shown in (1) in an ideal batch reactor is given in Figure 1 [1], which shows that if all the reactants are introduced into the reactor at reaction condition, the concentration of the desired product R initially rises and goes through a maximum, and then it reduces, whereas the concentration of undesired product $S$ keeps rising with time. The concentration of reactants continuously decreases and will become zero at infinite time.

As is the case with many industrial operations in FedBatch Reactor, when we add reactant B on to reactant A in reactor, initially product $\mathrm{R}$ forms favorably, and this $\mathrm{R}$ reacts further with $B$ to form $S$. After significant extent of reaction (i.e., after significant extent of $\mathrm{R}$ formation), if we keep adding $B$ in to the reaction mass, the concentration of $R$ will be significantly high, and that of A will be significantly 


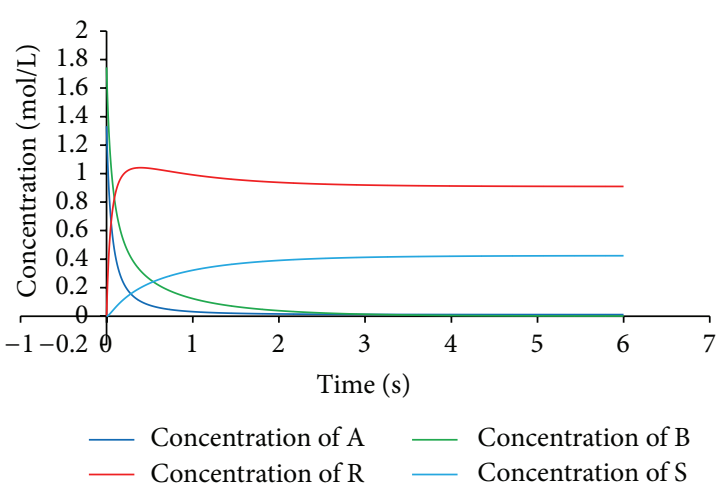

Figure 1: Concentration as a function of time.

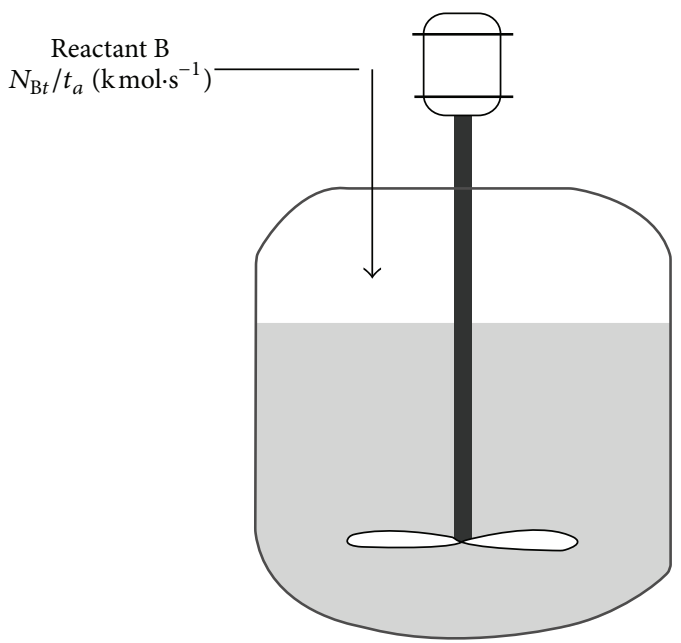

FIgURE 2: Schematic drawing of Fed-Batch Reactor.

less. Under this condition, with further fresh charge of $\mathrm{B}$, condition for $\mathrm{S}$ formation is favored. Both modes of operations (batch and semibatch or fed batch) would have reacting species concentration so varied with time that a quantitative analysis is imperative to understand the relative significance of these two reactors in the light of obtaining maximum product $\mathrm{R}$ yield. It has been reported in Chemical Reaction Engineering text book, Levenspiel [1], that, for an elementary second order competitive consecutive reaction, product, R, selectivity is the same in semi-batch (i.e., FedBatch Reactor) and Batch Reactors. Efforts have been made in the past to understand the factors affecting product selectivity of competitive consecutive reaction.

In the Reaction Engineering text books, Levenspiel [1] and Coulson and Richardson's [2], type of reactors (i.e., Plug Flow Reactors, Mixed Flow reactors, or Fed-Batch Reactor) and product selectivity have been discussed, especially for competitive consecutive reactions.

The recent literature on product selectivity of competitive consecutive reactions is reported by Shah et al. [3, 4], which deals with "product selectivity with mixing, reaction rates, and stoichiometry." As the reactions in actual are not necessarily always elementary [1], it is relevant to simulate the product selectivity of nonelementary second order competitive consecutive reaction schemes.

References [5, 6] deal with product selectivity and mixing and covering competitive consecutive reaction and competitive parallel reactions. This shows that identifying the conditions for increased product selectivity is an important aspect. At times, product selectivity determines the economics of operating a plant.

In practice, Batch reactors, unlike Fed Batch Reactor, offer higher order of nonideality in mixing and heat transfer in the form of significant concentration and temperature gradients, as it (Batch Reactor) has to deal with larger quantities of mass and heat energy from the very start of the time, 0 seconds. This necessitates the use of Fed-Batch mode of operations predominantly in Pharmaceuticals and other related industries. However, the continuous Plug Flow Reactors are known for their flexibility in offering higher heat transfer area and better mixing intensities. Of late, many pieces of literature and practical works have gone on investigating and implementing continuous Plug Flow Reactors in pharmaceutical and other related chemical industries. Designs have varied from a simple tube to a static mixer to plate heat exchanger type of reactors to Microreactors; one would see that in pieces of literature [7-12]. Anderson [7] reports that, in lab scale, $23 \%$ yield of desired intermediate product in a specific competitive consecutive reaction became $83 \%$ upon changing the mode of reaction from semi-batch to continuous plug flow. Brechtelsbauer and Ricard [8] report that static mixer based continuous Plug Flow Reactor gave a better product yield due to good turbulent and heat transfer characteristics. The major challenge in implementing Plug Flow Reactor in Pharmaceuticals and related other industries is in identifying the right reaction kinetics [13].

The primary aim of this simulation work is to find out a kinetic scenario, in which continuous Plug Flow Reactor would yield higher desired product than that the conventional Fed-Batch Reactor would yield. Also, this paper aims to provide a practical method to pick among the simulated reaction models the schemes, which would be kinetically favored in Plug Flow Reactor.

The rate equations governing the chemical reaction system, given in (1), is as follows [1]

$$
\begin{aligned}
& r_{\mathrm{A}}=-K_{1} C_{\mathrm{A}}^{a} C_{\mathrm{B}}^{b}, \\
& r_{\mathrm{B}}=-K_{1} C_{\mathrm{A}}^{a} C_{\mathrm{B}}^{b}-K_{2} C_{\mathrm{B}}^{c} C_{\mathrm{R}}^{d}, \\
& r_{\mathrm{R}}=K_{1} C_{\mathrm{A}}^{a} C_{\mathrm{B}}^{b}-K_{2} C_{\mathrm{B}}^{c} C_{\mathrm{R}}^{d}, \\
& r_{\mathrm{S}}=K_{2} C_{\mathrm{B}}^{c} C_{\mathrm{R}}^{d} .
\end{aligned}
$$

The exponents $a, b, c$, and $d$ represent the order of the reaction with respect to each of the reacting species. When $a=b=$ $c=d=1$, the reaction becomes an elementary second order reaction. Values other than 1 for any of the exponents make the reaction nonelementary. Here the analysis is limited to second order reactions; hence $a+b=c+d=2$ [1]. 


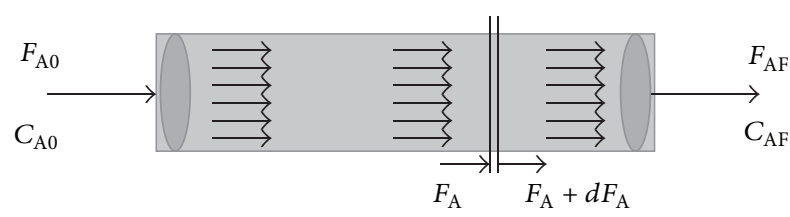

FIgURE 3: Schematic drawing of Plug Flow Reactor.

TABLE 1: Molecular weights.

\begin{tabular}{lccc}
\hline $\begin{array}{l}\text { Molecular weight of A } \\
\text { Molecular weight of B }\end{array}$ & 18.7500 & Molecular weight of R & 46.8750 \\
Molecular weight of C & 46.8750 \\
\hline $\begin{array}{l}\text { Total (1st reaction } \\
\text { reactants) }\end{array}$ & 93.7500 & $\begin{array}{c}\text { Total (1st reaction } \\
\text { products) }\end{array}$ & 93.7500 \\
\hline $\begin{array}{l}\text { Molecular weight of R } \\
\text { Molecular weight of B }\end{array}$ & 18.7500 & $\begin{array}{c}\text { Molecular weight of S } \\
\text { Molecular weight of D }\end{array}$ & 32.8125 \\
$\begin{array}{l}\text { Total (2nd reaction } \\
\text { reactants) }\end{array}$ & 65.6250 & $\begin{array}{c}\text { Total (2nd reaction } \\
\text { products) }\end{array}$ & 65.6250 \\
\hline
\end{tabular}

\section{The Fed-Batch Reactor (Reactor-1)}

Reactant $\mathrm{A}$ is taken in the reactor, whereas reactant $\mathrm{B}$ is added continuously over reactant A (see Figure 2). It is to be noted that component $\mathrm{B}$ is added (no output flow term), whereas component $\mathrm{A}$ is taken inside the reactor (no input flow term and no output flow term). Hence, material balance for components A and B must be written separately. Material balance pattern of all other products is similar to that of component A.

For Species A,

Input $=$ Output + Disappearance by Reaction

+ Accumulation,

$$
\begin{gathered}
0=0+\left(-r_{\mathrm{A}}\right) V+\left(\frac{d N_{\mathrm{A}}}{d t}\right), \\
\left(\frac{-1}{V}\right) \cdot\left(\frac{d N_{\mathrm{A}}}{d t}\right)=-r_{\mathrm{A}} .
\end{gathered}
$$

For Species B,

$$
\begin{aligned}
& \text { Input }= \text { Output }+ \text { Disappearance by Reaction } \\
&+ \text { Accumulation, } \\
&\left(\frac{N_{\mathrm{B} t}}{t_{a}}\right)=0+\left(-r_{\mathrm{B}}\right) V+\left(\frac{d N_{\mathrm{B}}}{d t}\right) \\
&\left(\frac{-1}{V}\right)\left(\frac{d N_{\mathrm{B}}}{d t}\right)=-r_{\mathrm{B}}-\left(\frac{N_{\mathrm{B} t}}{V t_{a}}\right) .
\end{aligned}
$$

From (3) to (4), we can mathematically describe the reaction system in ideal Fed-Batch Reactor as follows:

$$
\begin{array}{r}
\frac{d N_{\mathrm{A}}}{d_{t}}=\left(\frac{-1}{V}\right) K_{1} N_{\mathrm{A}}^{a} N_{\mathrm{B}}^{b}, \quad 0<t \leq t_{a}+t_{m}, \\
\frac{d N_{\mathrm{B}}}{d t}=\left(\frac{-1}{V}\right) K_{1} N_{\mathrm{A}}^{a} N_{\mathrm{B}}^{b}-\left(\frac{1}{V}\right) K_{2} N_{\mathrm{B}}^{c} N_{\mathrm{R}}^{d}+\frac{N_{\mathrm{B} t}}{t_{a}} ; \\
0<t \leq t_{a},
\end{array}
$$

$$
\begin{gathered}
\frac{d N_{\mathrm{B}}}{d t}=\left(\frac{-1}{V}\right) K_{1} N_{\mathrm{A}}^{a} N_{\mathrm{B}}^{b}-\left(\frac{1}{V}\right) K_{2} N_{\mathrm{B}}^{c} N_{\mathrm{R}}^{d}, \quad t_{a}<t \leq t_{a+m}, \\
\frac{d N_{\mathrm{R}}}{d t}=\left(\frac{1}{V}\right) K_{1} N_{\mathrm{A}}^{a} N_{\mathrm{B}}^{b}-\left(\frac{1}{V}\right) K_{2} N_{\mathrm{B}}^{c} N_{\mathrm{R}}^{d}, \quad 0<t \leq t_{a+m}, \\
\frac{d N_{\mathrm{S}}}{d t}=\left(\frac{1}{V}\right) K_{2} N_{\mathrm{B}}^{c} N_{\mathrm{R}}^{d}, \quad 0<t \leq t_{a+m}, \\
V=\frac{t V_{a t}}{t_{a}}+\left(V_{t}-V_{a t}\right), \quad 0<t \leq t_{a}, \\
V=V_{t}, \quad t_{a}<t \leq t_{a+m} .
\end{gathered}
$$

The sets of equations (5) represent in the second order consecutive competitive reaction in Fed-Batch Reactor.

\section{The Plug Flow Reactor (Reactor-2) (See Figure 3)}

The material (i.e., chemical) balance equations for a Plug Flow Reactor can be written as follows [1]:

$$
\begin{aligned}
& \text { Input }=\text { Output }+ \text { Disappearance by reaction } \\
& + \text { Accumulation, } \\
& F_{\mathrm{A}}=F_{\mathrm{A}}+d F_{\mathrm{A}}+\left(-r_{\mathrm{A}} \cdot d v\right), \\
& \left(\frac{-d F_{\mathrm{A}}}{d v}\right)=-r_{\mathrm{A}} \text {, } \\
& \left(\frac{-d C_{\mathrm{A}} v^{\prime}}{d v}\right)=-r_{\mathrm{A}} \text {. }
\end{aligned}
$$

Space time in Plug Flow Reactor, $t^{*}=v / v^{\prime}$

When volumetric flow rate is constant, $d t^{*}=d v / v^{\prime},(8)$ becomes as follows:

$$
\left(\frac{-d C_{\mathrm{A}}}{d t^{*}}\right)=-r_{\mathrm{A}}
$$

From (7) to (10), we can mathematically describe the reaction system in ideal Plug Flow Reactor as follows:

$$
\begin{aligned}
& \frac{d C_{\mathrm{A}}}{d t^{*}}=-K_{1} C_{\mathrm{A}}^{a} C_{\mathrm{B}}^{b}, \\
& \frac{d C_{\mathrm{B}}}{d t^{*}}=-K_{1} C_{\mathrm{A}}^{a} C_{\mathrm{B}}^{b}-K_{2} C_{\mathrm{B}}^{c} C_{\mathrm{R}}^{d}, \\
& \frac{d C_{\mathrm{R}}}{d t^{*}}=K_{1} C_{\mathrm{A}}^{a} C_{\mathrm{B}}^{b}-K_{2} C_{\mathrm{B}}^{c} C_{\mathrm{R}}^{d}, \\
& \frac{d C_{\mathrm{S}}}{d t^{*}}=K_{2} C_{\mathrm{B}}^{c} C_{\mathrm{R}}^{d}
\end{aligned}
$$

\section{Simulation Plan}

Solutions to the set of equations in (5) and (11) will enable one to analyze the performance of reaction system in Fed Batch Reactor and continuous Plug flow Reactor, respectively.

The main aim of this literature is to carry out the previously mentioned analysis for an arbitrary, still practically relevant, reaction system. 
TABle 2: (a) Reactor-1 (Fed-Batch, Scheme 1, Part 1). (b) Reactor-2 (Plug Flow, Scheme 1, Part 1). (c) Reactor-1 (Fed-Batch, Scheme 1, Part 2). (d) Reactor-2 (Plug Flow, Scheme 1, Part 2). (e) Reactor-1 (Fed-Batch, Scheme 1, Part 3). (f) Reactor-2 (Plug Flow, Scheme 1, Part 3).

(a)

\begin{tabular}{lccccccc}
\hline$t_{a}(\mathrm{~s})$ & $N_{\mathrm{B} t} / N_{\mathrm{A} t}$ & $V_{t}\left(\mathrm{~m}^{3}\right)$ & $N_{\mathrm{AF}}(\mathrm{k} \mathrm{mol})$ & $N_{\mathrm{BF}}(\mathrm{k} \mathrm{mol})$ & $N_{\mathrm{RF}}(\mathrm{k} \mathrm{mol})$ & $N_{\mathrm{SF}}(\mathrm{k} \mathrm{mol})$ & $W_{\mathrm{R}}(\mathrm{kg})$ \\
\hline 60 & 1.29 & 2.132 & 0.027 & 0.00 & 1.84 & 0.801 & 86.23 \\
600 & 1.29 & 2.132 & 0.027 & 0.00 & 1.84 & 0.8 & 86.24 \\
\hline
\end{tabular}

(b)

\begin{tabular}{lccccccc}
\hline$t_{\text {end }}(\mathrm{s})$ & $N_{\mathrm{Bt}} / N_{\mathrm{A} t}$ & $V_{t}\left(\mathrm{~m}^{3}\right)$ & $N_{\mathrm{AF}}(\mathrm{k} \mathrm{mol})$ & $N_{\mathrm{BF}}(\mathrm{k} \mathrm{mol})$ & $N_{\mathrm{RF}}(\mathrm{k} \mathrm{mol})$ & $N_{\mathrm{SF}}(\mathrm{k} \mathrm{mol})$ & $W_{\mathrm{R}}(\mathrm{kg})$ \\
\hline 6 & 1.291 & 2.132 & 0.026 & $1 E-26$ & 1.838 & 0.803 & 86.14 \\
60 & 1.291 & 2.132 & 0.026 & 0.00 & 1.838 & 0.803 & 86.14 \\
\hline
\end{tabular}

(c)

\begin{tabular}{lccccccc}
\hline$t_{a}(\mathrm{~s})$ & $N_{\mathrm{B} t} / N_{\mathrm{A} t}$ & $V_{t}\left(\mathrm{~m}^{3}\right)$ & $N_{\mathrm{AF}}(\mathrm{k} \mathrm{mol})$ & $N_{\mathrm{BF}}(\mathrm{k} \mathrm{mol})$ & $N_{\mathrm{RF}}(\mathrm{kmol})$ & $N_{\mathrm{SF}}(\mathrm{kmol})$ & $W_{\mathrm{R}}(\mathrm{kg})$ \\
\hline 450 & 1.29 & 2.132 & 0.027 & $2 E-06$ & 1.84 & 0.8 & 86.24 \\
900 & 1.29 & 2.132 & 0.027 & $1 E-06$ & 1.84 & 0.8 & 86.24 \\
1800 & 1.29 & 2.132 & 0.027 & $9 E-07$ & 1.84 & 0.8 & 86.24 \\
900 & 1.29 & 2.132 & 0.027 & $1 E-06$ & 1.84 & 0.8 & 86.24 \\
900 & 1.29 & 2.132 & 0.027 & $1 E-06$ & 1.84 & 0.8 & 86.24 \\
\hline
\end{tabular}

(d)

\begin{tabular}{lccccccc}
\hline$t_{\text {end }}(\mathrm{s})$ & $N_{\mathrm{Bt}} / N_{\mathrm{At}}$ & $V_{t}\left(\mathrm{~m}^{3}\right)$ & $N_{\mathrm{AF}}(\mathrm{k} \mathrm{mol})$ & $N_{\mathrm{BE}}(\mathrm{k} \mathrm{mol})$ & $N_{\mathrm{RF}}(\mathrm{k} \mathrm{mol})$ & $N_{\mathrm{SF}}(\mathrm{k} \mathrm{mol})$ & $W_{\mathrm{R}}(\mathrm{kg})$ \\
\hline 240 & 1.313 & 2.133 & 0.027 & 0.061 & 1.84 & 1.84 & 0.8 \\
360 & 1.296 & 2.132 & 0.027 & 0.016 & 1.84 & 0.8 & 0.8 \\
720 & 1.29 & 2.132 & 0.027 & $4 E-04$ & 1.84 & 0.8 & 86.24 \\
240 & 1.313 & 2.133 & 0.027 & 0.061 & 1.84 & 86.25 \\
240 & 1.313 & 2.133 & 0.027 & 0.061 & & 0.8 \\
\hline
\end{tabular}

(e)

\begin{tabular}{lccccccc}
\hline$t_{a}(\mathrm{~s})$ & $N_{\mathrm{B} t} / N_{\mathrm{A} t}$ & $V_{t}\left(\mathrm{~m}^{3}\right)$ & $N_{\mathrm{AF}}(\mathrm{k} \mathrm{mol})$ & $N_{\mathrm{BF}}(\mathrm{k} \mathrm{mol})$ & $N_{\mathrm{RF}}(\mathrm{k} \mathrm{mol})$ & $N_{\mathrm{SF}}(\mathrm{k} \mathrm{mol})$ & $W_{\mathrm{R}}(\mathrm{kg})$ \\
\hline 450 & 1.06 & 2.127 & 0.027 & 0.002 & 2.454 & 0.186 & 115.1 \\
900 & 1.06 & 2.127 & 0.027 & 0.001 & 2.454 & 0.186 & 115.1 \\
\hline
\end{tabular}

(f)

\begin{tabular}{lccccccc}
\hline$t_{\text {end }}(\mathrm{s})$ & $N_{\mathrm{Bt}} / N_{\mathrm{A} t}$ & $V_{t}\left(\mathrm{~m}^{3}\right)$ & $N_{\mathrm{AF}}(\mathrm{k} \mathrm{mol})$ & $N_{\mathrm{BF}}(\mathrm{k} \mathrm{mol})$ & $N_{\mathrm{RF}}(\mathrm{k} \mathrm{mol})$ & $N_{\mathrm{SF}}(\mathrm{k} \mathrm{mol})$ & $W_{\mathrm{R}}(\mathrm{kg})$ \\
\hline 240 & 1.117 & 2.128 & 0.027 & 0.152 & 2.454 & 0.186 & 115.1 \\
360 & 1.086 & 2.127 & 0.027 & 0.07 & 2.454 & 0.186 & 115.1 \\
\hline
\end{tabular}

Rate constant values are assumed with three individual scenarios: first one with ratio of $K_{1}$ to $K_{2}$ considered as 10 and $K_{1}$ considered as $100 \cdot$ Litre $\cdot \mathrm{mol}^{-1} \cdot \mathrm{s}^{-1}$, the second one with the same ratio of $K_{1} / K_{2}$ but with the $K_{1}$ as $0.1 \mathrm{Litre} \cdot \mathrm{mol}^{-1} \cdot \mathrm{s}^{-1}$, and the third one with the ratio of $K_{1} / K_{2}$ considered as 50 with the $K_{1}$ considered as $0.1 \mathrm{Litre} \cdot \mathrm{mol}^{-1} \cdot \mathrm{s}^{-1}$.

Totally, nine different sets of exponents (i.e., $a, b, c, d$ ) have been considered such that the overall order of reaction remains two. Hence, there are 9 sets of reactions schemes; each scheme is analyzed for the mentioned 3 sets of kinetic constants. Molecular weight of each of the components involved in the reaction is considered in consistent with the stoichiometry given in (1). The values are given in Table 1.

In this study, the molecular weights are used to convert moles into $\mathrm{Kg}$ and vice versa (molecular weight values are arbitrary in Table 1).

Total solvent quantity considered is $2 \mathrm{~m}^{3}$. Quantity of solvent, $\mathrm{m}^{3}$, used to make a stream of reactant A is called Sol
R. Quantity of solvent, $\mathrm{m}^{3}$, used to make a stream of reactant $\mathrm{B}$ is called Sol A. For the ensuing simulations, amount of solvent used in both the reacting streams is same, that is, Sol. $\mathrm{A} /($ Sol. $\mathrm{A}+$ Sol. $\mathrm{R})=0.5$, unless specified otherwise in the respective calculation/output data/graphs/Table. The effect of relative concentration of both the streams on kinetics is not treated at length; however, few cases with Sol. A/(Sol. R + Sol. A) $=0.25$ and 0.75 have been simulated to indicate the change in reaction selectivity with change in relative concentration of reactant streams.

As the reaction considered is in liquid phase, constant volume reaction system is supposed, except for the volume change due to addition of the solution of second component (reactant B) in to the solution of 1st component (reactant A) in the Fed-Batch Reactor. There is no volume change due to reaction. Volumetric flow rate in Plug Flow Reactor is considered constant. The volume in liters constituted by each of the starting materials ( $\mathrm{A}$ and $\mathrm{B}$ ) is assumed 0.5 times the weight in $\mathrm{kg}$ of the respective components. 


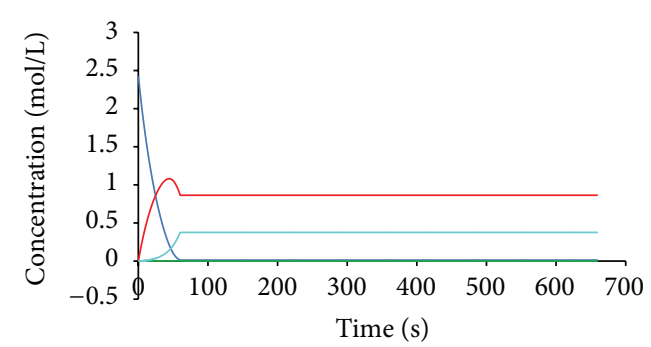

(a)

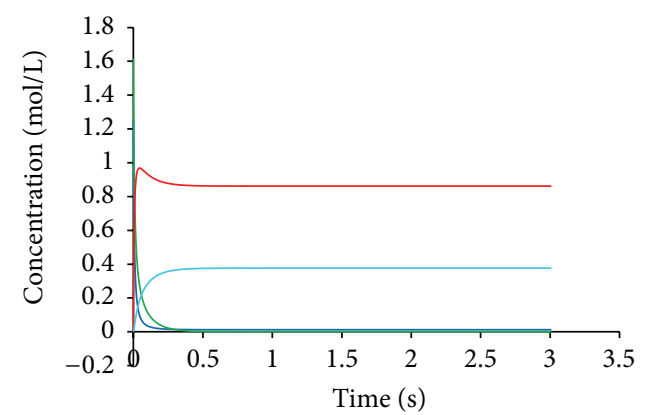

(c)

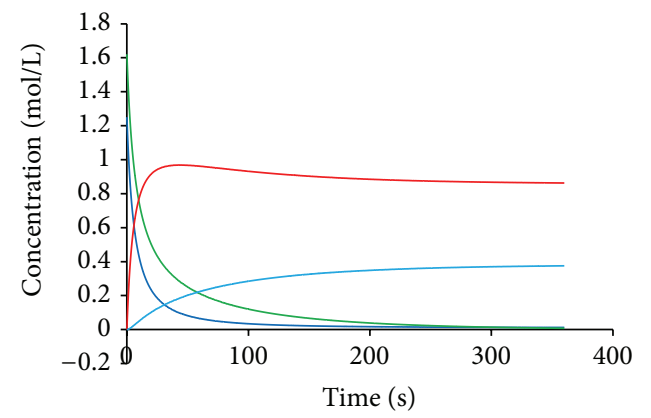

(e)

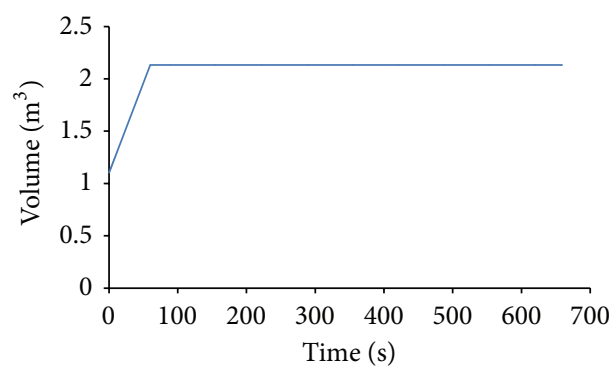

(b)

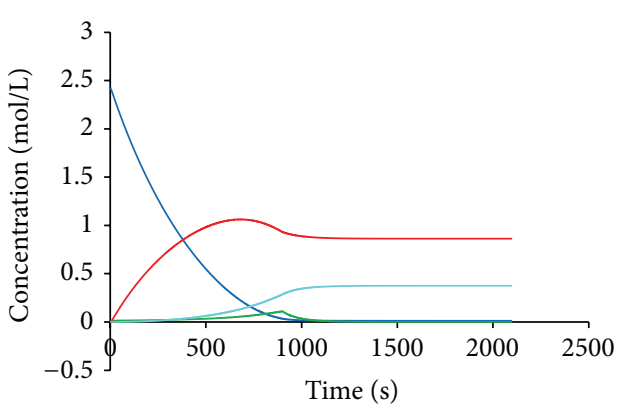

(d)

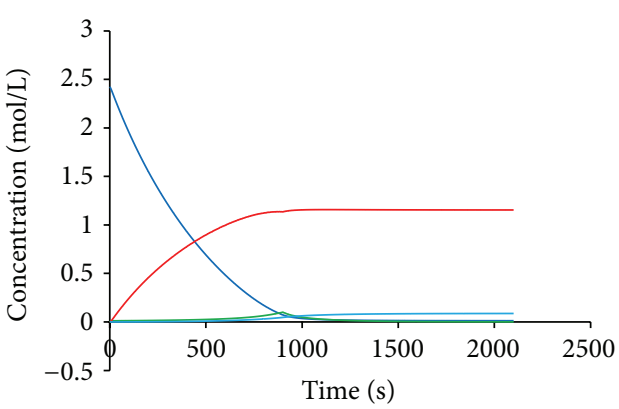

(f)

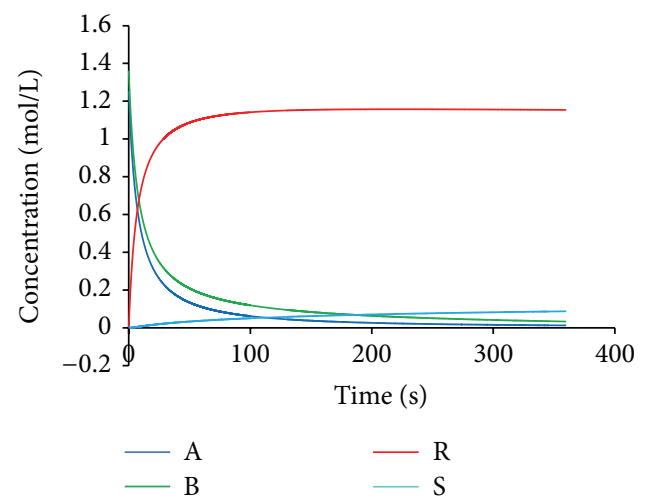

(g)

Figure 4: (a) Concentration as a function of time Fed-Batch Reactor (Scheme 1, Part 1, Case 1, $t_{a}=60 \mathrm{~s}, t_{m}=600 \mathrm{~s}$ (see Scheme 1 in Supplementary Material available online at http://dx.doi.org/10.1155/2013/591546). (b) Volume as a function of time Fed-Batch Reactor (Scheme 1 Part 1 Case-1, $t_{a}=60 \mathrm{~s}, t_{m}=600 \mathrm{~s}$ ). (c) Concentration as a function of time Plug Flow Reactor (Scheme 1, Part 1, $t_{\text {end }}=6 \mathrm{~s}$; for brevity graph is plotted for $3 \mathrm{~s}$ only). (d) Concentration as a function of time Fed-Batch Reactor (Scheme 1, Part 2, $t_{a}=900 \mathrm{~s}, t_{m}=1200 \mathrm{~s}$ ). (e) Concentration as a function of time Plug Flow Reactor, (Scheme 1, Part 2, $t_{\text {end }}=360 \mathrm{~s}$ ). (f) Concentration as a function of time Fed-Batch Reactor (Scheme 1, Part 3, $t_{a}=900 \mathrm{~s}, t_{m}=1200 \mathrm{~s}$ ). (g) Concentration as a function of time Plug Flow Reactor (Scheme 1, Part 3, $t_{\mathrm{end}}=360 \mathrm{~s}$ ). 


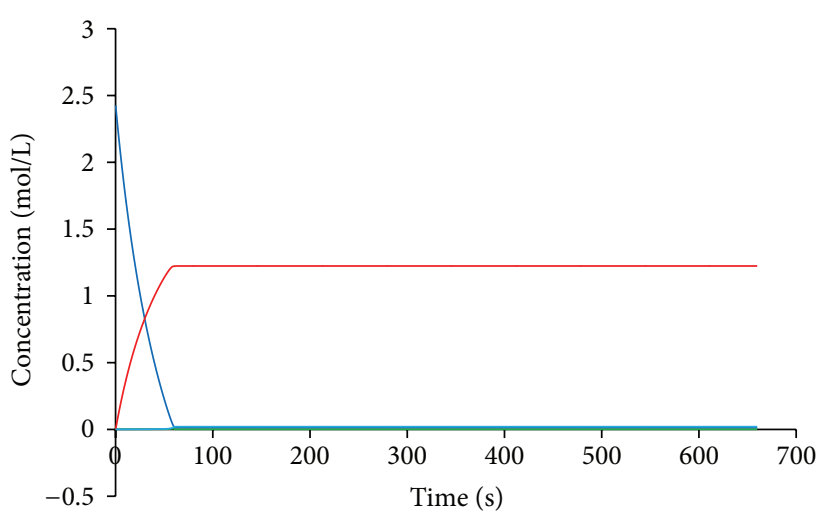

(a)

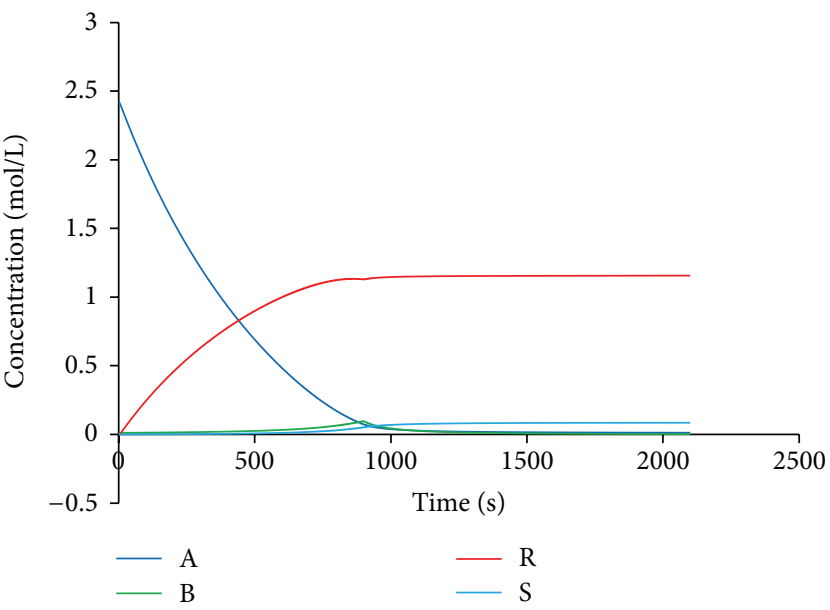

(c)

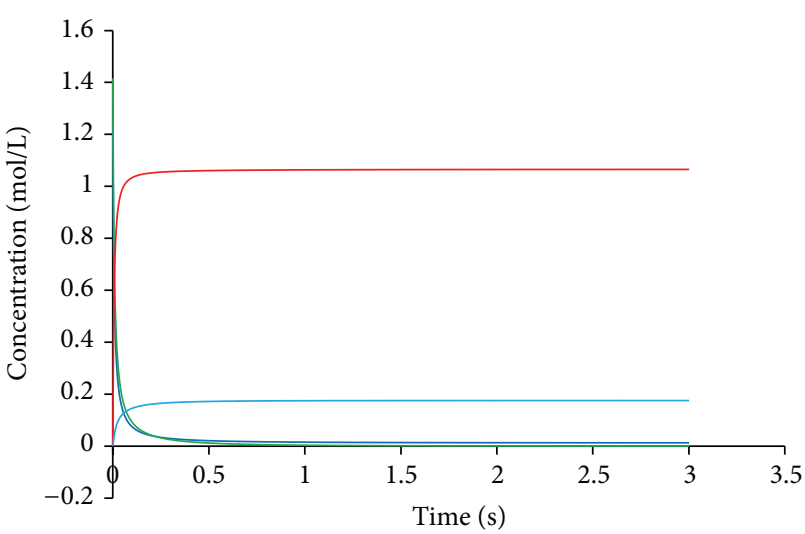

(b)

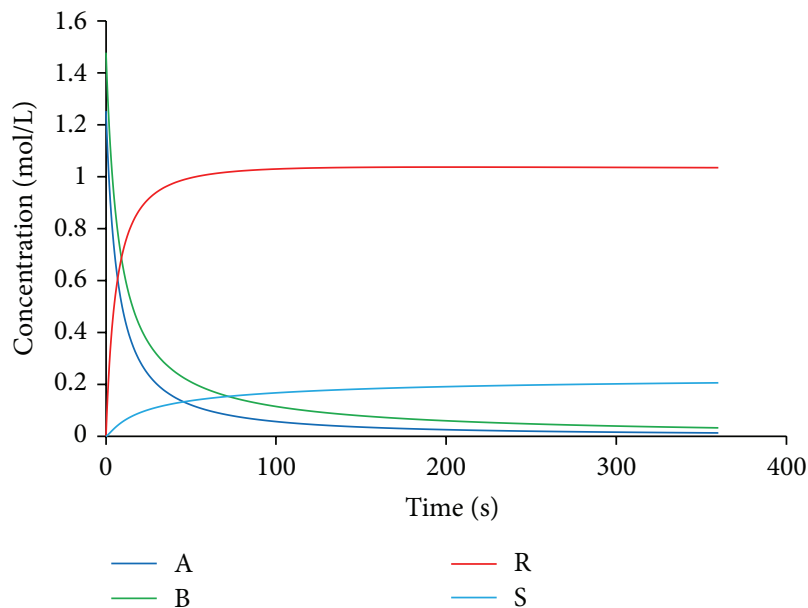

(d)

Figure 5: (a) Concentration as a function of time Fed-Batch Reactor (Scheme 2, Part 1, $t_{a}=60 \mathrm{~s}, t_{m}=600 \mathrm{~s}$ ). (b) Concentration as a function of time Plug Flow Reactor, (Scheme 2, Part 1, $t_{\text {end }}=6 \mathrm{~s}$; for brevity graph is plotted for $3 \mathrm{~s}$ only). (c) Concentration as a function of time Fed-Batch Reactor (Scheme 2, Part 2, $t_{a}=900 \mathrm{~s}, t_{m}=1200 \mathrm{~s}$ ). (d) Concentration as a function of time Plug Flow Reactor (Scheme 2, Part 2, $t_{\text {end }}=360 \mathrm{~s}$ ).

The quantity of A used in the entire study is $200 \mathrm{Kgs}$. In case of Fed batch reactor, the simulation has been done for various addition time of stream $B$; reaction maintenance time is chosen such that further change in concentration profile is practically absent. The constancy of concentration profile towards the end of $t_{m}$ can be observed in the concentration profiles obtained from MATLAB. Also, $t_{m}$ is maintained constant for a given set of $K_{1} / K_{2}$ in order to make the comparative study relevant. In case of Plug Flow Reactor, the simulation is done for different reaction end time as different case. The reaction time, $t_{\mathrm{end}}$, in Plug Flow Reactor refers to space time.

In case of Fed-Batch Reactor, the addition rate is considered constant across the entire addition time.

The reaction is run in both the reactors for a specified extent of conversion; that is, $99 \%$ of reactant A conversion is the reaction end point. For a prechosen $t_{a}, t_{m}$, and $t_{\text {end }}$, the $99 \%$ conversion of reactant $A$ is ensured by adjusting the total moles of reactant $\mathrm{B}$, that is, by adjusting $N_{\mathrm{B} t} / N_{\mathrm{A} t}$; final $99 \%$ conversion of reactant $\mathrm{A}$ is achieved for predefined cases of $t_{a}$ $(\mathrm{s}), t_{m}(\mathrm{~s})$, and $t_{\text {end }}(\mathrm{s})$.
The previously mentioned assumptions and basis have been considered keeping in mind that the actual reaction scenarios in the industry can be understood and interpreted in the light of the conclusions arrived at in this simulation study.

The concentration profiles given in the subsequent sections are intended only to showcase the pattern of the corresponding reaction scheme. The quantitative details of such graphs are given in the tables for the respective cases.

\section{Simulation Accuracy}

Solution to the previously mentioned simultaneous nonlinear differential equations ((5) and (11)) has been obtained by the software MATLAB, which entailed its default Explicit RungeKutta $(4,5)$ Variable step (Dormand-Prince Pair) method. The calculation tolerance has been set at a default $0.1 \%$ with step limits adjusted such that step limits $n$ and $n / 10$ seconds would return the final results matching up to 3 decimal points. When the gap between reactor- 1 and reactor2 results narrows/becomes more significant towards arriving 


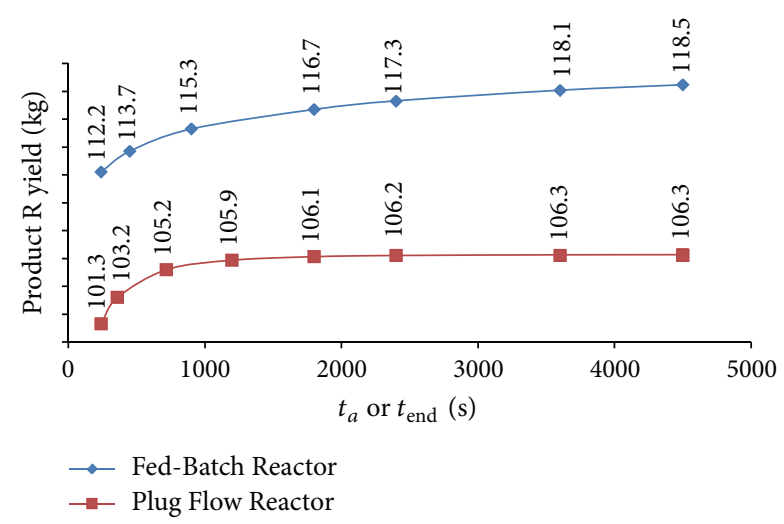

FIGURE 6: Product yield as a function of addition time and reaction end time in Fed Batch Reactor and Plug Flow Reactor, respectively (Scheme 2, Part 2).

at a conclusion, tolerance is squeezed further to $0.01 \%$ with the same step limit criteria as done for the simulation with tolerance $0.1 \%$.

\section{Simulation (Scheme 1, $a=b=c=d=1$, i.e., Elementary Reaction)}

7.1. Part 1 (Cases 1 and 2) $K_{1}=100, K_{1} / K_{2}=10$, and $K_{2}=10$. In Tables 2(a) and 2(b), simulation results for two cases have been captured. Figures 4(a) and 4(c) are sample concentration profiles of reaction species in ideal Fed Batch and ideal Plug Flow Reactor. Figure 4(b) is the graphical representation of reaction volume in Fed-Batch Reactor.

It can be observed in Figure 4(a) that, with $t_{m}=600 \mathrm{~s}$, further concentration change (reaction) is negligible. As the addition rate of reagent $B$ considered in this simulation study is constant, the fed batch volume increases linearly till $t=$ $t_{a}$. During Reaction maintenance time, $t_{m}$, the Fed-Batch volume remains constant.

7.2. Part 2 (Cases 1 to 5) $K_{1}=0.1, K_{1} / K_{2}=10$, and $K_{2}=$ 0.01 . Figures $4(\mathrm{~d})$ and $4(\mathrm{e})$ are sample concentration profiles of reaction species in ideal Fed Batch and ideal Plug Flow Reactors.

In Tables 2(c) and 2(d), results for all simulated cases have been captured, and the data lines (rows) 4 and 5 correspond to the fraction, Sol A/(Sol A + Sol R) $=0.25$ and 0.75 , respectively.

7.3. Part 3 (Cases 1 and 2) $K_{1}=0.1, K_{1} / K_{2}=50$, and $K_{2}=0.002$. Figures $4(\mathrm{f})$ and $4(\mathrm{~g})$ are sample concentration profiles of reaction species in ideal Fed Batch and ideal Plug Flow Reactors.

In Tables 2(e) and 2(f), simulation results for two cases have been captured.

Tables 2(a) to 2(f) show that elementary reaction of the type given in (1) yields the same amount of desired product in fed batch reactor and Plug Flow Reactor. Moreover, the yield values in Part 2 remain the same as those in Part 1 . That is because $K_{1} / K_{2}$ values remain the same in both Part 1 and Part 2 , even though the individual $K_{1}$ and $K_{2}$ values are different. It is to be noted that in Part 3, yield values are different from that in Part 1 and Part 2. That is because $K_{1} / K_{2}$ value in Part 3 is different from those in Part 1 and Part 2. The change in the relative concentration of both the reacting streams (as shown in Table 2(c) rows 2, 4, and 5, and Table 2(d) rows 1, 4, and 5) does not have any effect on the yield.

\section{Simulation (Scheme 2, $a=b=1, c=1.5, d=$ 0.5 , Nonelementary)}

8.1. Part 1 (Cases 1 and 2) $K_{1}=100, K_{1} / K_{2}=10$, and $K_{2}=10$. Figures $5(\mathrm{a})$ and $5(\mathrm{~b})$ are sample concentration profiles of reaction species in ideal Fed Batch and ideal Plug Flow Reactors.

In Tables 3(a) and 3(b), simulation results for two cases simulated have been captured.

8.2. Part 2 (Cases 1 to 5) $K_{1}=0.1, K_{1} / K_{2}=10$, and $K_{2}=$ 0.01 . Figures $5(\mathrm{c})$ and $5(\mathrm{~d})$ are sample concentration profiles of reaction species in ideal Fed Batch and ideal Plug Flow Reactors.

In Tables 3(c) and 3(d) and Figure 6, results for all the simulated cases have been captured. The data lines (rows) 4 and 5 in Tables 3(c) and 3(d) correspond to the fraction, Sol $\mathrm{A} /($ Sol $\mathrm{A}+\mathrm{Sol} \mathrm{R})=0.25$ and 0.75 , respectively.

The yield values for varying reaction times are captured in Figure 6.

8.3. Part 3 (Cases 1 and 2) $K_{1}=0.1, K_{1} / K_{2}=50$, and $K_{2}=$ 0.002 . In Tables $3(\mathrm{e})$ and $3(\mathrm{f})$, simulation results for two cases have been captured.

Tables 3(a) and 3(f) and Figure 6 show that this non elementary reaction yields higher desired product in FedBatch Reactor than in Continuous Plug Flow Reactor.

In Figure 6, the Plug Flow Reactor yield initially increases with the increase in reaction time (i.e., lengthier reactor pipe); consequently, $N_{\mathrm{B} t} / N_{\mathrm{A} t}$ value decreases, as shown in Tables $3(c)$ and 3(d). (i.e., reduced consumption of Reactant B). However, the Plug Flow Reactor yield saturates out below Fed-Batch Reactor yield. Overall, the Fed Batch Reactor yields higher product $\mathrm{R}$ than Plug Flow Reactor, even though there is a very marginal change in yield for the change in the relative concentration of reacting streams (Table 3(c), rows 2 , 4, and 5) in Fed Batch Reactor.

\section{Simulation (Scheme 3, $a=b=1, c=0.5, d=$ 1.5 , Nonelementary)}

9.1. Part 1 (Cases 1 and 2) $K_{1}=100, K_{1} / K_{2}=10$, and $K_{2}=10$. In Tables 4(a) and 4(b), simulation results for two cases have been captured.

Figures 7(a) and 7(b) are sample concentration profiles of reaction species in ideal Fed Batch and ideal Plug Flow Reactors. 
Table 3: (a) Reactor-1 (Fed-Batch, Scheme 2, Part 1). (b) Reactor-2 (Plug Flow, Scheme 2, Part 1). (c) Reactor-1 (Fed-Batch, Scheme 2, Part 2). (d) Reactor-2 (Plug Flow, Scheme 2, Part 2). (e) Reactor-1 (Fed-Batch, Scheme 2, Part 3). (f) Reactor-2 (Plug Flow, Scheme 2, Part 3).

(a)

\begin{tabular}{lccccccc}
\hline$t_{a}(\mathrm{~s})$ & $N_{\mathrm{Bt}} / N_{\mathrm{A} t}$ & $V_{t}\left(\mathrm{~m}^{3}\right)$ & $N_{\mathrm{AF}}(\mathrm{kmol})$ & $N_{\mathrm{BF}}(\mathrm{k} \mathrm{mol})$ & $N_{\mathrm{RF}}(\mathrm{k} \mathrm{mol})$ & $N_{\mathrm{SF}}(\mathrm{k} \mathrm{mol})$ & $W_{\mathrm{R}}(\mathrm{kg})$ \\
\hline 60 & 1.005 & 2.132 & 0.027 & 0.00 & 2.598 & 0.042 & 122 \\
600 & 0.996 & 2.125 & 0.027 & 0.00 & 2.625 & 0.015 & 123 \\
\hline
\end{tabular}

(b)

\begin{tabular}{lccccccc}
\hline$t_{\text {end }}(\mathrm{s})$ & $N_{\mathrm{Bt}} / N_{\mathrm{A} t}$ & $V_{t}\left(\mathrm{~m}^{3}\right)$ & $N_{\mathrm{AF}}(\mathrm{k} \mathrm{mol})$ & $N_{\mathrm{BF}}(\mathrm{k} \mathrm{mol})$ & $N_{\mathrm{RF}}(\mathrm{k} \mathrm{mol})$ & $N_{\mathrm{SF}}(\mathrm{k} \mathrm{mol})$ & $W_{\mathrm{R}}(\mathrm{kg})$ \\
\hline 6 & 1.13 & 2.128 & 0.027 & $6 E-06$ & 2.267 & 0.4 & 106.3 \\
60 & 1.13 & 2.128 & 0.027 & $3 E-35$ & 2.267 & 0.4 & 106.3 \\
\hline
\end{tabular}

(c)

\begin{tabular}{lccccccc}
\hline$t_{a}(\mathrm{~s})$ & $N_{\mathrm{Bt}} / N_{\mathrm{At}}$ & $V_{t}\left(\mathrm{~m}^{3}\right)$ & $N_{\mathrm{AF}}(\mathrm{k} \mathrm{mol})$ & $N_{\mathrm{BF}}(\mathrm{k} \mathrm{mol})$ & $N_{\mathrm{RF}}(\mathrm{k} \mathrm{mol})$ & $N_{\mathrm{SF}}(\mathrm{k} \mathrm{mol})$ & $W_{\mathrm{R}}(\mathrm{kg})$ \\
\hline 450 & 1.072 & 2.127 & 0.027 & 0.005 & 2.425 & 0.215 & 113.7 \\
900 & 1.059 & 2.166 & 0.027 & 0.004 & 2.459 & 0.181 & 115.3 \\
1800 & 1.048 & 2.126 & 0.027 & 0.004 & 2.491 & 0.149 & 116.7 \\
900 & 1.061 & 2.127 & 0.027 & 0.004 & 2.456 & 0.184 & 115.1 \\
900 & 1.058 & 2.126 & 0.027 & 0.004 & 2.463 & 0.177 & 115.4 \\
\hline
\end{tabular}

(d)

\begin{tabular}{lccccccc}
\hline$t_{\text {end }}(\mathrm{s})$ & $N_{\mathrm{Bt}} / N_{\mathrm{A} t}$ & $V_{t}\left(\mathrm{~m}^{3}\right)$ & $N_{\mathrm{AF}}(\mathrm{k} \mathrm{mol})$ & $N_{\mathrm{BF}}(\mathrm{k} \mathrm{mol})$ & $N_{\mathrm{RF}}(\mathrm{k} \mathrm{mol})$ & $N_{\mathrm{SF}}(\mathrm{k} \mathrm{mol})$ & $W_{\mathrm{R}}(\mathrm{kg})$ \\
\hline 240 & 1.221 & 2.131 & 0.027 & 0.135 & 2.16 & 0.48 & 101.3 \\
360 & 1.18 & 2.129 & 0.027 & 0.068 & 2.202 & 0.438 \\
720 & 1.145 & 2.129 & 0.027 & 0.018 & 2.244 & 0.396 \\
240 & 1.221 & 2.131 & 0.027 & 0.135 & 2.16 & 0.48 & 103.2 \\
240 & 1.221 & 2.131 & 0.027 & 0.135 & 2.16 & 0.48 & 101.3 \\
\hline
\end{tabular}

(e)

\begin{tabular}{lccccccc}
\hline$t_{a}(\mathrm{~s})$ & $N_{\mathrm{B} t} / N_{\mathrm{A} t}$ & $V_{t}\left(\mathrm{~m}^{3}\right)$ & $N_{\mathrm{AF}}(\mathrm{k} \mathrm{mol})$ & $N_{\mathrm{BF}}(\mathrm{k} \mathrm{mol})$ & $N_{\mathrm{RF}}(\mathrm{k} \mathrm{mol})$ & $N_{\mathrm{SF}}(\mathrm{k} \mathrm{mol})$ & $W_{\mathrm{R}}(\mathrm{kg})$ \\
\hline 450 & 1.009 & 2.125 & 0.027 & 0.008 & 2.599 & 0.041 & 121.8 \\
900 & 1.006 & 2.125 & 0.027 & 0.008 & 2.605 & 0.035 & 122.1 \\
\hline
\end{tabular}

(f)

\begin{tabular}{lccccccc}
\hline$t_{\text {end }}(\mathrm{s})$ & $N_{\mathrm{B} t} / N_{\mathrm{A} t}$ & $V_{t}\left(\mathrm{~m}^{3}\right)$ & $N_{\mathrm{AF}}(\mathrm{k} \mathrm{mol})$ & $N_{\mathrm{BF}}(\mathrm{k} \mathrm{mol})$ & $N_{\mathrm{RF}}(\mathrm{k} \mathrm{mol})$ & $N_{\mathrm{SF}}(\mathrm{k} \mathrm{mol})$ & $W_{\mathrm{R}}(\mathrm{kg})$ \\
\hline 240 & 1.094 & 2.127 & 0.027 & 0.083 & 2.545 & 0.095 & 119.3 \\
360 & 1.058 & 2.126 & 0.027 & 0.097 & 2.555 & 0.085 & 119.8 \\
\hline
\end{tabular}

9.2. Part 2 (Cases 1 to 5) $K_{1}=0.1, K_{1} / K_{2}=10$, and $K_{2}=$ 0.01 . In Tables 4(c) and 4(d) and Figure 8, results for other simulated cases have been captured.

The last two data lines (rows) in Tables 4(c) and 4(d) correspond to the fraction, Sol A/(Sol A + Sol R $)=0.25$ and 0.75 , respectively.

Figures $7(\mathrm{c})$ and $7(\mathrm{~d})$ are sample concentration profiles of reaction species in ideal Fed Batch and ideal Plug Flow Reactors.

The yield values for varying reaction times are captured in Figure 8.

9.3. Part 3 (Cases 1 and 2) $K_{1}=0.1, K_{1} / K_{2}=50$, and $K_{2}=$ 0.002 . In Tables 4(e) and 4(f), simulation results for two cases have been captured.

Tables 4(a)-4(f) and Figure 8 show that this non elementary reaction yields higher desired product, $\mathrm{R}$, in Plug Flow Reactor than in Fed-Batch Reactor.
It is to be noted that the reduced addition time in Fed Batch Reactor results in increased product yield. However, in actual practice, heat transfer and other limitations of the reactor vessel could possibly determine the minimum addition time beyond which addition time cannot be reduced. So, the Fed Batch reactor yield is limited.

It is to be further noted that there is a marginal change in the yield in Fed Batch reactor with the change in relative concentration of reacting streams (Table 4(c), rows 2, 4, and 5). However, this variation is too low to catch up with Plug Flow Reactor yield.

\section{Simulations (for the Rest of the Schemes)}

10.1. (Scheme 4, $a=0.5, b=1.5, c=0.5, d=1.5$, Nonelementary)

10.1.1. Part 1 (Cases 1 and 2) $K_{1}=100, K_{1} / K_{2}=10$, and $K_{2}=$ 10. See Tables 5(a) and 5(b). 
Table 4: (a) Reactor-1 (Fed-Batch, Scheme 3, Part 1). (b) Reactor-2 (Plug Flow, Scheme 3, Part 1). (c) Reactor-1 (Fed-Batch, Scheme 3 , Part 2). (d) Reactor-2 (Plug Flow, Scheme 3, Part 2). (e) Reactor-1 (Fed-Batch, Scheme 3, Part 3). (f) Reactor-2 (Plug Flow, Scheme 3, Part 3).

(a)

\begin{tabular}{lccccccc}
\hline$t_{a}(\mathrm{~s})$ & $N_{\mathrm{B} t} / N_{\mathrm{A} t}$ & $V_{t}\left(\mathrm{~m}^{3}\right)$ & $N_{\mathrm{AF}}(\mathrm{k} \mathrm{mol})$ & $N_{\mathrm{BF}}(\mathrm{k} \mathrm{mol})$ & $N_{\mathrm{RF}}(\mathrm{k} \mathrm{mol})$ & $N_{\mathrm{SF}}(\mathrm{k} \mathrm{mol})$ & $W_{\mathrm{R}}(\mathrm{kg})$ \\
\hline 60 & 1.909 & 2.148 & 0.027 & 0.00 & 0.19 & 2.45 & 9 \\
600 & 1.95 & 2.149 & 0.027 & 0.00 & 0.079 & 2.561 & 4 \\
\hline
\end{tabular}

(b)

\begin{tabular}{lccccccc}
\hline$t_{\text {end }}(\mathrm{s})$ & $N_{\mathrm{Bt}} / N_{\mathrm{A} t}$ & $V_{t}\left(\mathrm{~m}^{3}\right)$ & $N_{\mathrm{AF}}(\mathrm{k} \mathrm{mol})$ & $N_{\mathrm{BF}}(\mathrm{k} \mathrm{mol})$ & $N_{\mathrm{RF}}(\mathrm{k} \mathrm{mol})$ & $N_{\mathrm{SF}}(\mathrm{k} \mathrm{mol})$ & $W_{\mathrm{R}}(\mathrm{kg})$ \\
\hline 6 & 1.448 & 2.136 & 0.027 & $3 E-08$ & 1.419 & 1.2 & 66.52 \\
60 & 1.447 & 2.136 & 0.027 & $3 E-05$ & 1.42 & 1.2 & 66.57 \\
\hline
\end{tabular}

(c)

\begin{tabular}{lccccccc}
\hline$t_{a}(\mathrm{~s})$ & $N_{\mathrm{B} t} / N_{\mathrm{A} t}$ & $V_{t}\left(\mathrm{~m}^{3}\right)$ & $N_{\mathrm{AF}}(\mathrm{k} \mathrm{mol})$ & $N_{\mathrm{BF}}(\mathrm{k} \mathrm{mol})$ & $N_{\mathrm{RF}}(\mathrm{k} \mathrm{mol})$ & $N_{\mathrm{SF}}(\mathrm{k} \mathrm{mol})$ & $W_{\mathrm{R}}(\mathrm{kg})$ \\
\hline 450 & 1.598 & 2.14 & 0.027 & $5 E-13$ & 1.019 & 0.651 & 1.789 \\
900 & 1.661 & 2.142 & 0.027 & $3 E-13$ & 0.687 & 1.953 & 39.89 \\
1800 & 1.722 & 2.143 & 0.027 & $7 E-13$ & 0.868 & 1.772 & 40.67 \\
900 & 1.655 & 2.141 & 0.027 & $1 E-12$ & 0.833 & 1.807 \\
900 & 1.668 & 2.142 & 0.027 & $1 E-12$ & & 39.05 \\
\hline
\end{tabular}

(d)

\begin{tabular}{lccccccc}
\hline$t_{\text {end }}(\mathrm{s})$ & $N_{\mathrm{Bt}} / N_{\mathrm{A} t}$ & $V_{t}\left(\mathrm{~m}^{3}\right)$ & $N_{\mathrm{AF}}(\mathrm{k} \mathrm{mol})$ & $N_{\mathrm{BF}}(\mathrm{k} \mathrm{mol})$ & $N_{\mathrm{RF}}(\mathrm{k} \mathrm{mol})$ & $N_{\mathrm{SF}}(\mathrm{kmol})$ & $W_{\mathrm{R}}(\mathrm{kg})$ \\
\hline 240 & 1.448 & 2.136 & 0.027 & $4 E-12$ & 1.419 & 1.221 & 66.52 \\
360 & 1.448 & 2.136 & 0.027 & $4 E-12$ & 1.419 & 1.221 & 1.221 \\
720 & 1.448 & 2.136 & 0.027 & $4 E-12$ & 1.419 & 1.221 & 66.52 \\
240 & 1.448 & 2.136 & 0.027 & $4 E-12$ & 1.419 & 66.52 \\
240 & 1.448 & 2.136 & 0.027 & $4 E-12$ & & 66.52 \\
\hline
\end{tabular}

(e)

\begin{tabular}{lccccccc}
\hline$t_{a}(\mathrm{~s})$ & $N_{\mathrm{B} t} / N_{\mathrm{A} t}$ & $V_{t}\left(\mathrm{~m}^{3}\right)$ & $N_{\mathrm{AF}}(\mathrm{k} \mathrm{mol})$ & $N_{\mathrm{BF}}(\mathrm{k} \mathrm{mol})$ & $N_{\mathrm{RF}}(\mathrm{k} \mathrm{mol})$ & $N_{\mathrm{SF}}(\mathrm{k} \mathrm{mol})$ & $W_{\mathrm{R}}(\mathrm{kg})$ \\
\hline 450 & 1.214 & 2.13 & 0.027 & 0.000 & 2.043 & 0.597 & 95.75 \\
900 & 1.251 & 2.131 & 0.027 & 0.000 & 1.943 & 0.697 & 91.07 \\
\hline
\end{tabular}

(f)

\begin{tabular}{lccccccc}
\hline$t_{\text {end }}(\mathrm{s})$ & $N_{\mathrm{B} t} / N_{\mathrm{A} t}$ & $V_{t}\left(\mathrm{~m}^{3}\right)$ & $N_{\mathrm{AF}}(\mathrm{k} \mathrm{mol})$ & $N_{\mathrm{BF}}(\mathrm{k} \mathrm{mol})$ & $N_{\mathrm{RF}}(\mathrm{k} \mathrm{mol})$ & $N_{\mathrm{SF}}(\mathrm{k} \mathrm{mol})$ & $W_{\mathrm{R}}(\mathrm{kg})$ \\
\hline 240 & 1.172 & 2.129 & 0.027 & 0.071 & 2.227 & 0.413 & 104.4 \\
360 & 1.163 & 2.129 & 0.027 & 0.003 & 2.182 & 0.458 & 102.3 \\
\hline
\end{tabular}

10.1.2. Part 2 (Cases 1 to 5) $K_{1}=0.1, K_{1} / K_{2}=10$, and $K_{2}=$ 0.01 . The data lines (rows) 4 and 5 in Tables 5(c) and 5(d) correspond to the fraction, Sol A/(Sol A + Sol R $)=0.25$ and 0.75 , respectively.

The yield values for varying reaction times are captured in Figure 9.

10.1.3. Part 3 (Cases 1 and 2) $K_{1}=0.1, K_{1} / K_{2}=50$, and $K_{2}=$ 0.002 (See Tables 5(e) and 5(f)). Tables 5(a)-5(f) and Figure 9 show that this non elementary reaction yields higher desired product in Plug Flow Reactor than in Fed-Batch Reactor.

As in Scheme 3, the reduced addition time in Fed Batch Reactor results in increased product yield. However, in actual practice, heat transfer and other limitations of the reactor vessel could possibly determine the minimum addition time beyond which addition time cannot be reduced. So, the Fed Batch reactor yield is limited.
The marginal change in the yield in Fed Batch reactor with relative concentration of reacting streams (Table 5(c), rows 2, 4, and 5) may be noted. However, this variation is too low to catch up with Plug Flow Reactor yield.

10.2. (Scheme 5, $a=1.5, b=0.5, c=0.5, d=1.5$,
Nonelementary)

10.2.1. Part 1 (Cases 1 and 2) $K_{1}=100, K_{1} / K_{2}=10$, and $K_{2}=10$. See Tables 6(a) and 6(b).

10.2.2. Part 2 (Cases 1 to 5) $K_{1}=0.1, K_{1} / K_{2}=10, K_{2}=$ 0.01. In Table 6(c) and 6(d), the data lines (rows) 4 and 5 correspond to the fraction, Sol A/(Sol A + Sol R $)=0.25$ and 0.75 , respectively.

10.2.3. Part 3 (Cases 1 and 2) $K_{1}=0.1, K_{1} / K_{2}=50, K_{2}=$ 0.002 (See Tables 6(e) and 6(f)). Tables 6(a)-6(f) show that 


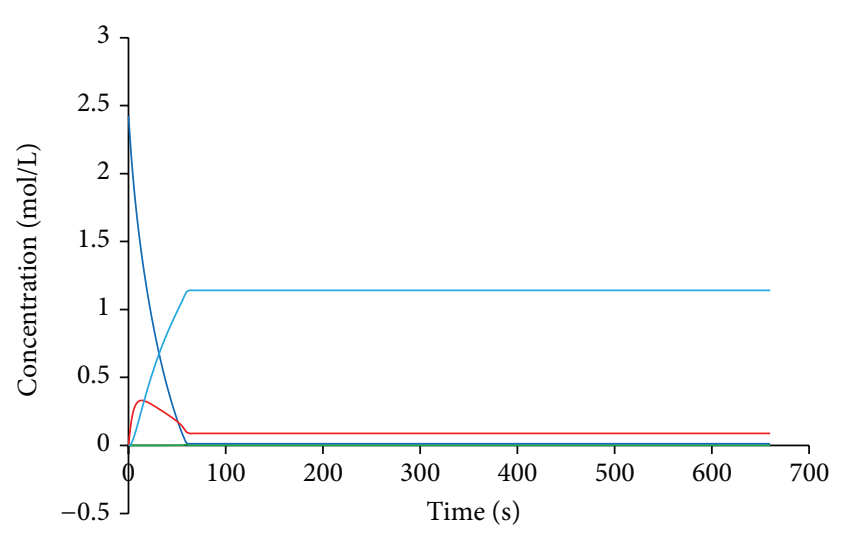

(a)

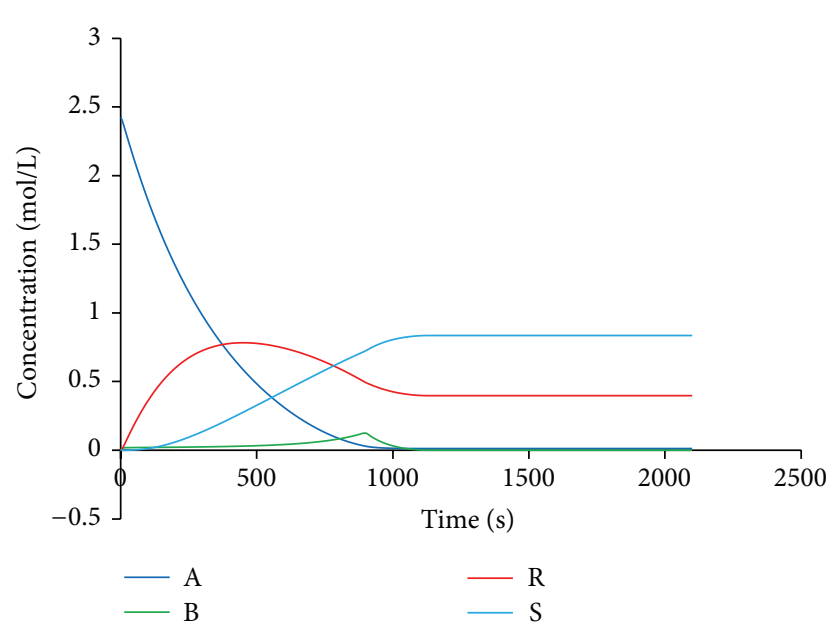

(c)

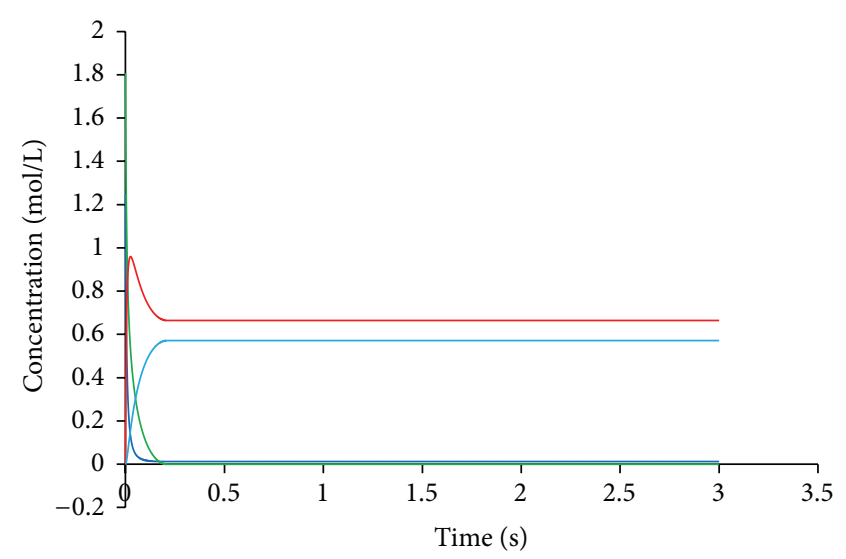

(b)

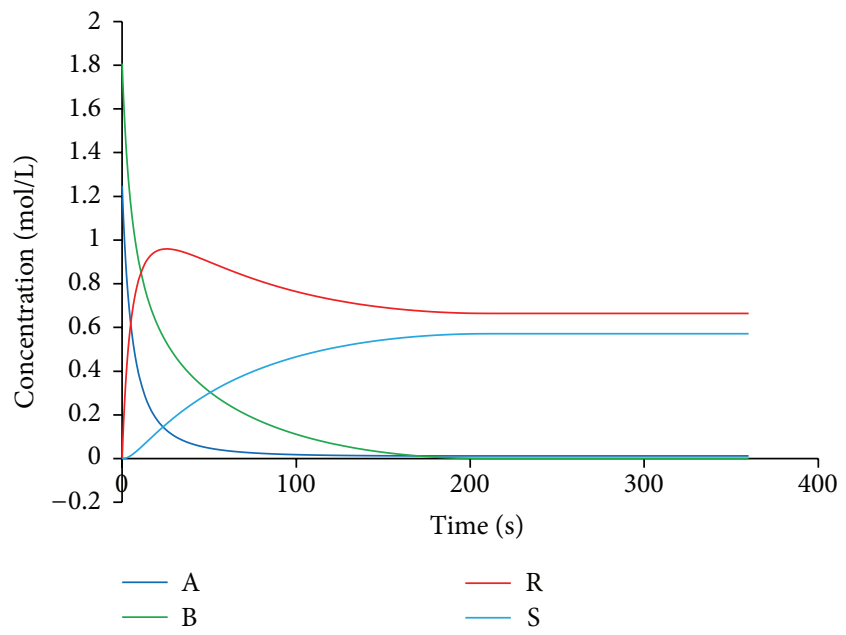

(d)

FIgURE 7: (a) Concentration as a function of time Fed-Batch Reactor (Scheme 3, Part 1, $t_{a}=60 \mathrm{~s}, t_{m}=600 \mathrm{~s}$ ). (b) Concentration as a function of time Plug Flow Reactor, (Scheme 3, Part $1, t_{\text {end }}=6 \mathrm{~s}$; for brevity graph is plotted for $3 \mathrm{~s}$ only). (c) Concentration as a function of time Fed-Batch Reactor (Scheme 3, Part 2, $t_{a}=900 \mathrm{~s}, t_{m}=1200 \mathrm{~s}$ ). (d) Concentration as a function of time Plug Flow Reactor (Scheme 3, Part 2, $\left.t_{\text {end }}=360 \mathrm{~s}\right)$.

this type of nonelementary reaction yields the same amount of desired product in fed batch reactor and in Plug Flow Reactor. Moreover, the yield values in Part 2 remain the same as those in Part 1 . That is because $K_{1} / K_{2}$ values remain the same in both Part 1 and Part 2, even though the individual $K_{1}$ and $K_{2}$ values are different. It is to be noted that in Part 3, yield values are different from that in Part 1 and Part 2. That is because $K_{1} / K_{2}$ value in Part 3 is different from those in Part 1 and Part 2.

The change in the relative concentration of both the reacting streams (as shown in Table 6(c) rows 2, 4, and 5, and Table $6(\mathrm{~d})$ rows 1,4 , and 5) does not have any effect on the yield.

10.3. (Scheme 6, $a=0.5, b=1.5, c=1.5, d=0.5$,
Nonelementary)

10.3.1. Part 1 (Cases 1 and 2) $K_{1}=100, K_{1} / K_{2}=10$, and $K_{2}=10$. See Tables 7(a) and 7(b).
10.3.2. Part 2 (Cases 1 to 5) $K_{1}=0.1, K_{1} / K_{2}=10$, and $K_{2}=$ 0.01. In Tables 7(c) and 7(d), the data lines (rows) 4 and 5 correspond to the fraction, Sol A/(Sol A + Sol R $)=0.25$ and 0.75 , respectively.

10.3.3. Part 3 (Cases 1 and 2) $K_{1}=0.1, K_{1} / K_{2}=50$, and $K_{2}=$ 0.002 (See Tables $7(e)$ and $7(f)$ ). Tables $7(a)-7(f)$ show that this type of nonelementary reaction also behaves similar to elementary reaction and nonelementary reaction Scheme 5, with respect to product selectivity; that is, the yield is the same in both the reactors. The change in the relative concentration of both the reacting streams (as shown in Table 7(c) rows 2, 4 , and 5, and Table $7(\mathrm{~d})$ rows 1,4 , and 5) does not have any effect on the yield.

10.4. (Scheme 7, $a=1.5, b=0.5, c=1.5, d=0.5$, Nonelementary)

10.4.1. Part 1 (Cases 1 and 2) $K_{1}=100, K_{1} / K_{2}=10$, and $K_{2}=10$. See Tables 8(a) and 8(b). 
Table 5: (a) Reactor-1 (Fed-Batch, Scheme 4, Part 1). (b) Reactor-2 (Plug Flow, Scheme 4, Part 1). (c) Reactor-1 (Fed-Batch, Scheme 4, Part 2). (d) Reactor-2 (Plug Flow, Scheme 4, Part 2). (e) Reactor-1 (Fed-Batch, Scheme 4, Part 3). (f) Reactor-2 (Plug Flow, Scheme 4, Part 3).

(a)

\begin{tabular}{lccccccc}
\hline$t_{a}(\mathrm{~s})$ & $N_{\mathrm{B} t} / N_{\mathrm{A} t}$ & $V_{t}\left(\mathrm{~m}^{3}\right)$ & $N_{\mathrm{AF}}(\mathrm{k} \mathrm{mol})$ & $N_{\mathrm{BF}}(\mathrm{k} \mathrm{mol})$ & $N_{\mathrm{RF}}(\mathrm{k} \mathrm{mol})$ & $N_{\mathrm{SF}}(\mathrm{k} \mathrm{mol})$ & $W_{\mathrm{R}}(\mathrm{kg})$ \\
\hline 60 & 1.927 & 2.148 & 0.027 & 0.00 & 0.141 & 2.499 & 7 \\
600 & 1.961 & 2.149 & 0.027 & 0.00 & 0.05 & 2.59 & 2 \\
\hline
\end{tabular}

(b)

\begin{tabular}{lccccccc}
\hline$t_{\text {end }}(\mathrm{s})$ & $N_{\mathrm{Bt}} / N_{\mathrm{A} t}$ & $V_{t}\left(\mathrm{~m}^{3}\right)$ & $N_{\mathrm{AF}}(\mathrm{k} \mathrm{mol})$ & $N_{\mathrm{BF}}(\mathrm{k} \mathrm{mol})$ & $N_{\mathrm{RF}}(\mathrm{kmol})$ & $N_{\mathrm{SF}}(\mathrm{kmol})$ & $W_{\mathrm{R}}(\mathrm{kg})$ \\
\hline 6 & 1.313 & 2.133 & 0.027 & $6 E-08$ & 1.778 & 0.9 & 83.34 \\
60 & 1.313 & 2.667 & 0.027 & $6 E-08$ & 1.778 & 0.9 & 83.34 \\
\hline
\end{tabular}

(c)

\begin{tabular}{lccccccc}
\hline$t_{a}(\mathrm{~s})$ & $N_{\mathrm{B} t} / N_{\mathrm{A} t}$ & $V_{t}\left(\mathrm{~m}^{3}\right)$ & $N_{\mathrm{AF}}(\mathrm{k} \mathrm{mol})$ & $N_{\mathrm{BF}}(\mathrm{k} \mathrm{mol})$ & $N_{\mathrm{RF}}(\mathrm{k} \mathrm{mol})$ & $N_{\mathrm{SF}}(\mathrm{k} \mathrm{mol})$ & $W_{\mathrm{R}}(\mathrm{kg})$ \\
\hline 450 & 1.562 & 2.139 & 0.027 & 0.00 & 1.113 & 0.869 & 1.527 \\
900 & 1.654 & 2.141 & 0.027 & $1 E-10$ & 0.658 & 1.771 & 1.982 \\
1800 & 1.733 & 2.143 & 0.027 & $6 E-13$ & 0.868 & 1.75 & 30.75 \\
900 & 1.646 & 2.141 & 0.027 & $1 E-12$ & 0.848 & 1.792 \\
900 & 1.662 & 2.142 & 0.027 & $1 E-10$ & & & 39.74 \\
\hline
\end{tabular}

(d)

\begin{tabular}{lccccccc}
\hline$t_{\text {end }}(\mathrm{s})$ & $N_{\mathrm{Bt}} / N_{\mathrm{A} t}$ & $V_{t}\left(\mathrm{~m}^{3}\right)$ & $N_{\mathrm{AF}}(\mathrm{k} \mathrm{mol})$ & $N_{\mathrm{BF}}(\mathrm{k} \mathrm{mol})$ & $N_{\mathrm{RF}}(\mathrm{k} \mathrm{mol})$ & $N_{\mathrm{SF}}(\mathrm{kmol})$ & $W_{\mathrm{R}}(\mathrm{kg})$ \\
\hline 240 & 1.313 & 2.133 & 0.027 & 0.00 & 1.778 & 1.778 & 0.862 \\
360 & 1.313 & 2.133 & 0.027 & 0.00 & 1.778 & 0.862 & 0.862 \\
720 & 1.313 & 2.133 & 0.027 & $8 E-12$ & 1.778 & 0.862 & 83.34 \\
240 & 1.313 & 2.133 & 0.027 & 0.00 & 1.778 & 0.862 \\
240 & 1.313 & 2.133 & 0.027 & 0.00 & & 83.34 \\
\hline
\end{tabular}

(e)

\begin{tabular}{lccccccc}
\hline$t_{a}(\mathrm{~s})$ & $N_{\mathrm{B} t} / N_{\mathrm{A} t}$ & $V_{t}\left(\mathrm{~m}^{3}\right)$ & $N_{\mathrm{AF}}(\mathrm{k} \mathrm{mol})$ & $N_{\mathrm{BF}}(\mathrm{k} \mathrm{mol})$ & $N_{\mathrm{RF}}(\mathrm{k} \mathrm{mol})$ & $N_{\mathrm{SF}}(\mathrm{k} \mathrm{mol})$ & $W_{\mathrm{R}}(\mathrm{kg})$ \\
\hline 450 & 1.203 & 2.13 & 0.027 & $7 E-11$ & 2.071 & 0.569 & 97.1 \\
900 & 1.265 & 2.132 & 0.027 & $6 E-11$ & 1.907 & 0.733 & 89.4 \\
\hline
\end{tabular}

(f)

\begin{tabular}{lccccccc}
\hline$t_{\text {end }}(\mathrm{s})$ & $N_{\mathrm{B} t} / N_{\mathrm{A} t}$ & $V_{t}\left(\mathrm{~m}^{3}\right)$ & $N_{\mathrm{AF}}(\mathrm{k} \mathrm{mol})$ & $N_{\mathrm{BF}}(\mathrm{k} \mathrm{mol})$ & $N_{\mathrm{RF}}(\mathrm{k} \mathrm{mol})$ & $N_{\mathrm{SF}}(\mathrm{k} \mathrm{mol})$ & $W_{\mathrm{R}}(\mathrm{kg})$ \\
\hline 240 & 2.997 & 2.128 & 0.027 & 0.021 & 2.304 & 0.336 & 108 \\
360 & 1.124 & 2.128 & 0.027 & 0.00 & 2.284 & 0.356 & 107 \\
\hline
\end{tabular}

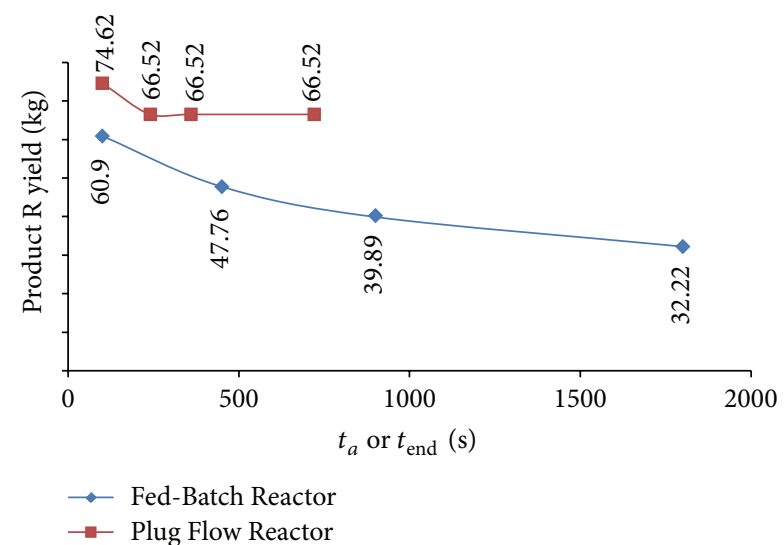

Figure 8: Product yield as a function of addition time and reaction end time in Fed Batch Reactor and Plug Flow Reactor, respectively (Scheme 3, Part 2).

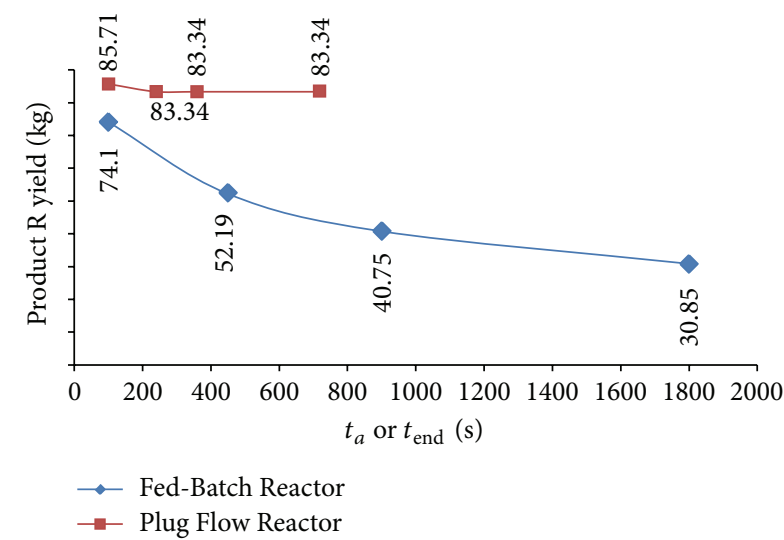

FIGURE 9: Product yield as a function of addition time and reaction end time in Fed Batch Reactor and Plug Flow Reactor, respectively (Scheme 4, Part 2). 
TABle 6: (a) Reactor-1 (Fed-Batch, Scheme 5, Part 1). (b) Reactor-2 (Plug Flow, Scheme 5, Part 2). (c) Reactor-1 (Fed-Batch, Scheme 5, Part 2). (d) Reactor-2 (Plug Flow, Scheme 5, Part 2). (e) Reactor-1 (Fed-Batch, Scheme 5, Part 2). (f) Reactor-2 (Plug Flow, Scheme 5, Part 2).

(a)

\begin{tabular}{lccccccc}
\hline$t_{a}(\mathrm{~s})$ & $N_{\mathrm{B} t} / N_{\mathrm{A} t}$ & $V_{t}\left(\mathrm{~m}^{3}\right)$ & $N_{\mathrm{AF}}(\mathrm{k} \mathrm{mol})$ & $N_{\mathrm{BF}}(\mathrm{k} \mathrm{mol})$ & $N_{\mathrm{RF}}(\mathrm{k} \mathrm{mol})$ & $N_{\mathrm{SF}}(\mathrm{k} \mathrm{mol})$ & $W_{\mathrm{R}}(\mathrm{kg})$ \\
\hline 60 & 1.664 & 2.142 & 0.027 & 0.00 & 0.843 & 1.797 & 39.54 \\
600 & 1.664 & 2.149 & 0.027 & 0.00 & 0.843 & 1.797 & 39.54 \\
\hline
\end{tabular}

(b)

\begin{tabular}{lccccccc}
\hline$t_{\text {end }}(\mathrm{s})$ & $N_{\mathrm{Bt}} / N_{\mathrm{A} t}$ & $V_{t}\left(\mathrm{~m}^{3}\right)$ & $N_{\mathrm{AF}}(\mathrm{k} \mathrm{mol})$ & $N_{\mathrm{BF}}(\mathrm{k} \mathrm{mol})$ & $N_{\mathrm{RF}}(\mathrm{k} \mathrm{mol})$ & $N_{\mathrm{SF}}(\mathrm{kmol})$ & $W_{\mathrm{R}}(\mathrm{kg})$ \\
\hline 6 & 1.664 & 2.142 & 0.027 & $6 E-09$ & 0.843 & 1.8 & 39.54 \\
60 & 1.664 & 2.142 & 0.027 & $6 E-09$ & 0.843 & 1.8 & 39.54 \\
\hline
\end{tabular}

(c)

\begin{tabular}{lccccccc}
\hline$t_{a}(\mathrm{~s})$ & $N_{\mathrm{B} t} / N_{\mathrm{A} t}$ & $V_{t}\left(\mathrm{~m}^{3}\right)$ & $N_{\mathrm{AF}}(\mathrm{k} \mathrm{mol})$ & $N_{\mathrm{BF}}(\mathrm{k} \mathrm{mol})$ & $N_{\mathrm{RF}}(\mathrm{k} \mathrm{mol})$ & $N_{\mathrm{SF}}(\mathrm{k} \mathrm{mol})$ & $W_{\mathrm{R}}(\mathrm{kg})$ \\
\hline 450 & 1.664 & 2.142 & 0.027 & $1 E-10$ & 0.844 & 0.843 & 3.796 \\
900 & 1.664 & 2.142 & 0.027 & $1 E-10$ & 0.843 & 1.797 & 1.797 \\
1800 & 1.664 & 2.142 & 0.027 & $1 E-10$ & 0.843 & 1.797 & 39.54 \\
900 & 1.664 & 2.142 & 0.027 & $1 E-10$ & 0.843 & 39.54 \\
900 & 1.664 & 2.142 & 0.027 & $1 E-10$ & & & 39.597 \\
\hline
\end{tabular}

(d)

\begin{tabular}{lccccccc}
\hline$t_{\text {end }}(\mathrm{s})$ & $N_{\mathrm{B} t} / N_{\mathrm{A} t}$ & $V_{t}\left(\mathrm{~m}^{3}\right)$ & $N_{\mathrm{AF}}(\mathrm{k} \mathrm{mol})$ & $N_{\mathrm{BF}}(\mathrm{k} \mathrm{mol})$ & $N_{\mathrm{RF}}(\mathrm{k} \mathrm{mol})$ & $N_{\mathrm{SF}}(\mathrm{kmol})$ & $W_{\mathrm{R}}(\mathrm{kg})$ \\
\hline 240 & 1.794 & 2.145 & 0.027 & 0.348 & 0.843 & 0.844 & 1.797 \\
360 & 1.672 & 2.142 & 0.027 & 0.022 & 0.843 & 1.796 & 1.797 \\
720 & 1.664 & 2.142 & 0.027 & 0.00 & 0.843 & 1.797 & 39.54 \\
240 & 1.794 & 2.145 & 0.027 & 0.348 & 0.843 & 1.797 \\
240 & 1.794 & 2.145 & 0.027 & 0.348 & & 39.54 \\
\hline
\end{tabular}

(e)

\begin{tabular}{lccccccc}
\hline$t_{a}(\mathrm{~s})$ & $N_{\mathrm{B} t} / N_{\mathrm{A} t}$ & $V_{t}\left(\mathrm{~m}^{3}\right)$ & $N_{\mathrm{AF}}(\mathrm{k} \mathrm{mol})$ & $N_{\mathrm{BF}}(\mathrm{k} \mathrm{mol})$ & $N_{\mathrm{RF}}(\mathrm{k} \mathrm{mol})$ & $N_{\mathrm{SF}}(\mathrm{k} \mathrm{mol})$ & $W_{\mathrm{R}}(\mathrm{kg})$ \\
\hline 450 & 1.24 & 2.131 & 0.027 & $7 E-11$ & 1.973 & 0.667 & 92.49 \\
900 & 1.24 & 2.131 & 0.027 & $7 E-11$ & 1.973 & 0.667 & 92.48 \\
\hline
\end{tabular}

(f)

\begin{tabular}{lccccccc}
\hline$t_{\text {end }}(\mathrm{s})$ & $N_{\mathrm{B} t} / N_{\mathrm{A} t}$ & $V_{t}\left(\mathrm{~m}^{3}\right)$ & $N_{\mathrm{AF}}(\mathrm{k} \mathrm{mol})$ & $N_{\mathrm{BF}}(\mathrm{k} \mathrm{mol})$ & $N_{\mathrm{RF}}(\mathrm{k} \mathrm{mol})$ & $N_{\mathrm{SF}}(\mathrm{k} \mathrm{mol})$ & $W_{\mathrm{R}}(\mathrm{kg})$ \\
\hline 240 & 1.442 & 2.136 & 0.027 & 0.537 & 1.973 & 0.667 & 92.47 \\
360 & 1.277 & 2.132 & 0.027 & 0.099 & 1.973 & 0.667 & 92.48 \\
\hline
\end{tabular}

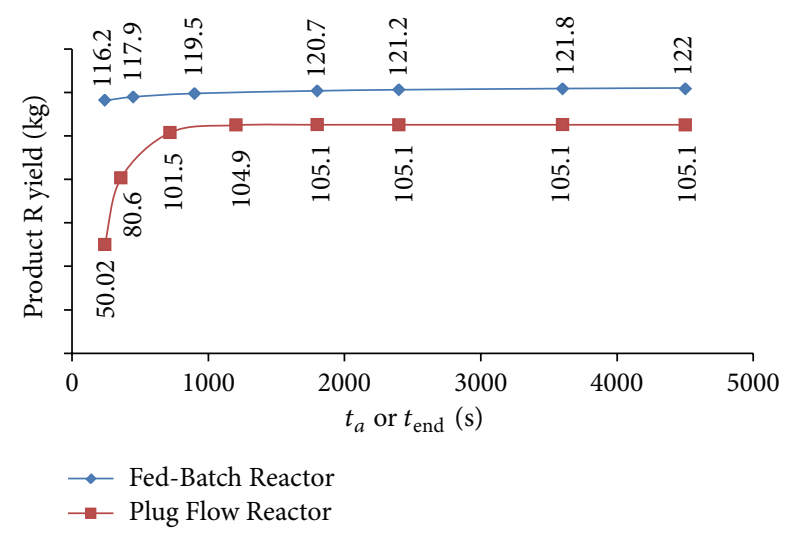

FIgURE 10: Product yield as a function of addition time and reaction end time in Fed Batch Reactor and Plug Flow Reactor, respectively (Scheme 7, Part 2).
10.4.2. Part 2 (Cases 1 to 5) $K_{1}=0.1, K_{1} / K_{2}=10$, and $K_{2}=$ 0.01. In Tables $8(\mathrm{c})$ and $8(\mathrm{~d})$, the data lines (rows) 4 and 5 correspond to the fraction, Sol A/(Sol A + Sol R $)=0.25$ and 0.75 , respectively.

The yield values for varying reaction times are captured in Figure 10.

10.4.3. Part 3 (Cases 1 and 2) $K_{1}=0.1, K_{1} / K_{2}=50$, and $K_{2}=0.002$ (See Tables $8(c)$ and $8(d)$ ). Tables $7(a)-$ $7(d)$ and Figure 10 show that this non elementary reaction yields higher desired product in Fed-Batch Reactor than in Continuous Plug Flow Reactor.

As in Scheme 2, the Plug Flow Reactor yield initially increases with the increase in reaction time, (i.e., lengthier reactor pipe); consequently, $N_{\mathrm{B} t} / N_{\mathrm{A} t}$ value decreases, as shown in Table $8(d)$ (i.e., reduced consumption of Reactant B). However, the Plug Flow Reactor yield saturates out below 
Table 7: (a) Reactor-1 (Fed-Batch, Scheme 6, Part 1). (b) Reactor-2 (Plug Flow, Scheme 6, Part 1). (c) Reactor-1 (Fed-Batch, Scheme 6, Part 2). (d) Reactor-2 (Plug Flow, Scheme 6, Part 2). (e) Reactor-1 (Fed-Batch, Scheme 6, Part 3). (f) Reactor-2 (Plug Flow, Scheme 6, Part 3).

(a)

\begin{tabular}{lccccccc}
\hline$t_{a}(\mathrm{~s})$ & $N_{\mathrm{B} t} / N_{\mathrm{A} t}$ & $V_{t}\left(\mathrm{~m}^{3}\right)$ & $N_{\mathrm{AF}}(\mathrm{k} \mathrm{mol})$ & $N_{\mathrm{BF}}(\mathrm{k} \mathrm{mol})$ & $N_{\mathrm{RF}}(\mathrm{k} \mathrm{mol})$ & $N_{\mathrm{SF}}(\mathrm{k} \mathrm{mol})$ & $W_{\mathrm{R}}(\mathrm{kg})$ \\
\hline 60 & 1.121 & 2.128 & 0.027 & 0.00 & 2.29 & 0.35 & 107.3 \\
600 & 1.121 & 2.128 & 0.027 & 0.00 & 2.29 & 0.35 & 107.3 \\
\hline
\end{tabular}

(b)

\begin{tabular}{lccccccc}
\hline$t_{\text {end }}(\mathrm{s})$ & $N_{\mathrm{Bt}} / N_{\mathrm{A} t}$ & $V_{t}\left(\mathrm{~m}^{3}\right)$ & $N_{\mathrm{AF}}(\mathrm{k} \mathrm{mol})$ & $N_{\mathrm{BF}}(\mathrm{k} \mathrm{mol})$ & $N_{\mathrm{RF}}(\mathrm{k} \mathrm{mol})$ & $N_{\mathrm{SF}}(\mathrm{kmol})$ & $W_{\mathrm{R}}(\mathrm{kg})$ \\
\hline 6 & 1.121 & 2.128 & 0.027 & $4 E-04$ & 2.29 & 0.4 & 107.3 \\
60 & 1.121 & 2.128 & 0.027 & $5 E-06$ & 2.29 & 0.4 & 107.3 \\
\hline
\end{tabular}

(c)

\begin{tabular}{lccccccc}
\hline$t_{a}(\mathrm{~s})$ & $N_{\mathrm{B} t} / N_{\mathrm{A} t}$ & $V_{t}\left(\mathrm{~m}^{3}\right)$ & $N_{\mathrm{AF}}(\mathrm{k} \mathrm{mol})$ & $N_{\mathrm{BF}}(\mathrm{k} \mathrm{mol})$ & $N_{\mathrm{RF}}(\mathrm{k} \mathrm{mol})$ & $N_{\mathrm{SF}}(\mathrm{k} \mathrm{mol})$ & $W_{\mathrm{R}}(\mathrm{kg})$ \\
\hline 450 & 1.124 & 2.128 & 0.027 & $7 E-03$ & 2.29 & 2.29 & 0.35 \\
900 & 1.124 & 2.128 & 0.027 & $7 E-03$ & 2.29 & 0.35 & 0.35 \\
1800 & 1.124 & 2.128 & 0.027 & $7 E-03$ & 2.29 & 0.35 & 107.3 \\
900 & 1.124 & 2.128 & 0.027 & $7 E-03$ & 2.29 & 0.35 \\
900 & 1.124 & 2.128 & 0.027 & $7 E-03$ & 107.3 \\
\hline
\end{tabular}

(d)

\begin{tabular}{lccccccc}
\hline$t_{\text {end }}(\mathrm{s})$ & $N_{\mathrm{Bt}} / N_{\mathrm{A} t}$ & $V_{t}\left(\mathrm{~m}^{3}\right)$ & $N_{\mathrm{AF}}(\mathrm{k} \mathrm{mol})$ & $N_{\mathrm{BF}}(\mathrm{k} \mathrm{mol})$ & $N_{\mathrm{RF}}(\mathrm{k} \mathrm{mol})$ & $N_{\mathrm{SF}}(\mathrm{k} \mathrm{mol})$ & $W_{\mathrm{R}}(\mathrm{kg})$ \\
\hline 240 & 1.152 & 2.129 & 0.027 & 0.083 & 2.29 & 2.29 & 0.35 \\
360 & 1.139 & 2.128 & 0.027 & 0.048 & 2.29 & 0.35 & 107.3 \\
720 & 1.128 & 2.128 & 0.027 & 0.017 & 2.29 & 0.35 & 0.35 \\
240 & 1.152 & 2.129 & 0.027 & 0.083 & 2.29 & 0.35 \\
240 & 1.152 & 2.129 & 0.027 & 0.083 & & 107.3 \\
\hline
\end{tabular}

(e)

\begin{tabular}{lccccccc}
\hline$t_{a}(\mathrm{~s})$ & $N_{\mathrm{B} t} / N_{\mathrm{A} t}$ & $V_{t}\left(\mathrm{~m}^{3}\right)$ & $N_{\mathrm{AF}}(\mathrm{k} \mathrm{mol})$ & $N_{\mathrm{BF}}(\mathrm{k} \mathrm{mol})$ & $N_{\mathrm{RF}}(\mathrm{k} \mathrm{mol})$ & $N_{\mathrm{SF}}(\mathrm{k} \mathrm{mol})$ & $W_{\mathrm{R}}(\mathrm{kg})$ \\
\hline 450 & 1.022 & 2.126 & 0.027 & 0.012 & 2.568 & 0.073 & 120.4 \\
900 & 1.022 & 2.126 & 0.027 & 0.012 & 2.567 & 0.072 & 120.3 \\
\hline
\end{tabular}

(f)

\begin{tabular}{lccccccc}
\hline$t_{\text {end }}(\mathrm{s})$ & $N_{\mathrm{B} t} / N_{\mathrm{A} t}$ & $V_{t}\left(\mathrm{~m}^{3}\right)$ & $N_{\mathrm{AF}}(\mathrm{k} \mathrm{mol})$ & $N_{\mathrm{BF}}(\mathrm{k} \mathrm{mol})$ & $N_{\mathrm{RF}}(\mathrm{k} \mathrm{mol})$ & $N_{\mathrm{SF}}(\mathrm{k} \mathrm{mol})$ & $W_{\mathrm{R}}(\mathrm{kg})$ \\
\hline 240 & 1.058 & 2.126 & 0.027 & 0.108 & 2.567 & 0.072 & 120.4 \\
360 & 1.042 & 2.126 & 0.027 & 0.066 & 2.568 & 0.073 & 120.4 \\
\hline
\end{tabular}

Fed-Batch Reactor yield (Figure 10). Overall, the Fed Batch Reactor yields higher product $\mathrm{R}$ than Plug Flow Reactor, even though there is a very marginal change in yield for the change in the relative concentration of reacting streams (Table $8(\mathrm{c})$, rows 2,4 , and 5 ).

10.5. (Scheme 8, $a=0.5, b=1.5, c=1, d=1$, Nonelementary)

10.5.1. Part 1 (Cases 1 and 2) $K_{1}=100, K_{1} / K_{2}=10$, and $K_{2}=10$. See Tables 9 (a) and $9(\mathrm{~b})$.

10.5.2. Part 2 (Cases 1 to 5) $K_{1}=0.1, K_{1} / K_{2}=10$, and $K_{2}=$ 0.01. In Tables 9 (c) and $9(\mathrm{~d})$, the data lines (rows) 4 and 5 correspond to the fraction, Sol A/(Sol A + Sol R $)=0.25$ and 0.75 , respectively.
The yield values for varying reaction times are captured in Figure 11.

10.5.3. Part 3 (Cases 1 and 2) $K_{1}=0.1, K_{1} / K_{2}=50$, and $K_{2}=0.002$ (See Tables 9(e) and $9(f)$ ). Tables 9(a)-9(f) and Figure 11 show that this non elementary reaction yields higher desired product in Plug Flow Reactor than in FedBatch Reactor. Also, the yield in Fed batch reactor decreases with addition time.

As in Scheme 3 and Scheme 4, the reduced addition time in Fed Batch Reactor results in increased product yield. However, in actual practice, heat transfer and other limitations of the reactor vessel could possibly determine the minimum addition time beyond which addition time cannot be reduced. So, the Fed Batch reactor yield is limited.

It is to be noted that there is a marginal change in the yield in Fed Batch reactor with relative concentration of reacting 
Table 8: (a) Reactor-1 (Fed-Batch, Scheme 7, Part 1). (b) Reactor-2 (Plug Flow, Scheme 7, Part 1). (c) Reactor-1 (Fed-Batch, Scheme 7, Part 2). (d) Reactor-2 (Plug Flow, Scheme 7, Part 2). (e) Reactor-1 (Fed-Batch, Scheme 7, Part 3). (f) Reactor-2 (Plug Flow, Scheme 7, Part 3).

(a)

\begin{tabular}{lccccccc}
\hline$t_{a}(\mathrm{~s})$ & $N_{\mathrm{B} t} / N_{\mathrm{A} t}$ & $V_{t}\left(\mathrm{~m}^{3}\right)$ & $N_{\mathrm{AF}}(\mathrm{k} \mathrm{mol})$ & $N_{\mathrm{BF}}(\mathrm{k} \mathrm{mol})$ & $N_{\mathrm{RF}}(\mathrm{k} \mathrm{mol})$ & $N_{\mathrm{SF}}(\mathrm{k} \mathrm{mol})$ & $W_{\mathrm{R}}(\mathrm{kg})$ \\
\hline 60 & 0.992 & 2.125 & 0.026 & 0.00 & 2.636 & 0.004 & 123.6 \\
600 & 0.99 & 2.125 & 0.027 & 0.00 & 2.64 & $8 E-05$ & 123.7 \\
\hline
\end{tabular}

(b)

\begin{tabular}{lccccccc}
\hline$t_{\text {end }}(\mathrm{s})$ & $N_{\mathrm{Bt}} / N_{\mathrm{A} t}$ & $V_{t}\left(\mathrm{~m}^{3}\right)$ & $N_{\mathrm{AF}}(\mathrm{k} \mathrm{mol})$ & $N_{\mathrm{BF}}(\mathrm{k} \mathrm{mol})$ & $N_{\mathrm{RF}}(\mathrm{k} \mathrm{mol})$ & $N_{\mathrm{SF}}(\mathrm{kmol})$ & $W_{\mathrm{R}}(\mathrm{kg})$ \\
\hline 6 & 1.139 & 2.128 & 0.027 & $2 E-11$ & 2.242 & 0.4 & 105.1 \\
60 & 1.139 & 2.128 & 0.027 & $2 E-11$ & 2.242 & 0.4 & 105.1 \\
\hline
\end{tabular}

(c)

\begin{tabular}{lccccccc}
\hline$t_{a}(\mathrm{~s})$ & $N_{\mathrm{B} t} / N_{\mathrm{A} t}$ & $V_{t}\left(\mathrm{~m}^{3}\right)$ & $N_{\mathrm{AF}}(\mathrm{k} \mathrm{mol})$ & $N_{\mathrm{BF}}(\mathrm{k} \mathrm{mol})$ & $N_{\mathrm{RF}}(\mathrm{k} \mathrm{mol})$ & $N_{\mathrm{SF}}(\mathrm{k} \mathrm{mol})$ & $W_{\mathrm{R}}(\mathrm{kg})$ \\
\hline 450 & 1.037 & 2.126 & 0.027 & $5 E-04$ & 2.515 & 2.548 & 0.092 \\
900 & 1.024 & 2.126 & 0.027 & $3 E-04$ & 2.576 & 0.064 & 117.9 \\
1800 & 1.014 & 2.125 & 0.027 & $1 E-04$ & 2.547 & 0.093 & 120.7 \\
900 & 1.025 & 2.126 & 0.027 & $3 E-04$ & 2.55 & 0.09 & 119.4 \\
900 & 1.024 & 2.126 & 0.027 & $3 E-04$ & & \\
\hline
\end{tabular}

(d)

\begin{tabular}{lccccccc}
\hline$t_{\text {end }}(\mathrm{s})$ & $N_{\mathrm{Bt}} / N_{\mathrm{A} t}$ & $V_{t}\left(\mathrm{~m}^{3}\right)$ & $N_{\mathrm{AF}}(\mathrm{k} \mathrm{mol})$ & $N_{\mathrm{BF}}(\mathrm{k} \mathrm{mol})$ & $N_{\mathrm{RF}}(\mathrm{k} \mathrm{mol})$ & $N_{\mathrm{SF}}(\mathrm{kmol})$ & $W_{\mathrm{R}}(\mathrm{kg})$ \\
\hline 240 & 1.757 & 2.144 & 0.027 & 0.472 & 1.067 & 1.573 & 50.02 \\
360 & 1.397 & 2.135 & 0.027 & 0.165 & 2.166 & 0.92 & 0.474 \\
720 & 1.176 & 2.129 & 0.027 & 0.021 & 1.067 & 1.573 & 101.5 \\
240 & 1.757 & 2.144 & 0.027 & 0.472 & 1.067 & 50.02 \\
240 & 1.757 & 2.144 & 0.027 & 0.472 & & 1.573 \\
\hline
\end{tabular}

(e)

\begin{tabular}{lccccccc}
\hline$t_{a}(\mathrm{~s})$ & $N_{\mathrm{B} t} / N_{\mathrm{A} t}$ & $V_{t}\left(\mathrm{~m}^{3}\right)$ & $N_{\mathrm{AF}}(\mathrm{k} \mathrm{mol})$ & $N_{\mathrm{BF}}(\mathrm{k} \mathrm{mol})$ & $N_{\mathrm{RF}}(\mathrm{k} \mathrm{mol})$ & $N_{\mathrm{SF}}(\mathrm{k} \mathrm{mol})$ & $W_{\mathrm{R}}(\mathrm{kg})$ \\
\hline 450 & 0.998 & 2.125 & 0.027 & 0.001 & 2.619 & 0.021 & 122.8 \\
900 & 0.996 & 2.125 & 0.027 & $9 E-04$ & 2.624 & 0.016 & 123.0 \\
\hline
\end{tabular}

(f)

\begin{tabular}{lccccccc}
\hline$t_{\text {end }}(\mathrm{s})$ & $N_{\mathrm{B} t} / N_{\mathrm{A} t}$ & $V_{t}\left(\mathrm{~m}^{3}\right)$ & $N_{\mathrm{AF}}(\mathrm{k} \mathrm{mol})$ & $N_{\mathrm{BF}}(\mathrm{k} \mathrm{mol})$ & $N_{\mathrm{RF}}(\mathrm{k} \mathrm{mol})$ & $N_{\mathrm{SF}}(\mathrm{k} \mathrm{mol})$ & $W_{\mathrm{R}}(\mathrm{kg})$ \\
\hline 240 & 1.372 & 2.134 & 0.027 & 0.687 & 2.309 & 0.331 & 108.2 \\
360 & 1.15 & 2.129 & 0.027 & 0.258 & 2.472 & 0.168 & 115.9 \\
\hline
\end{tabular}

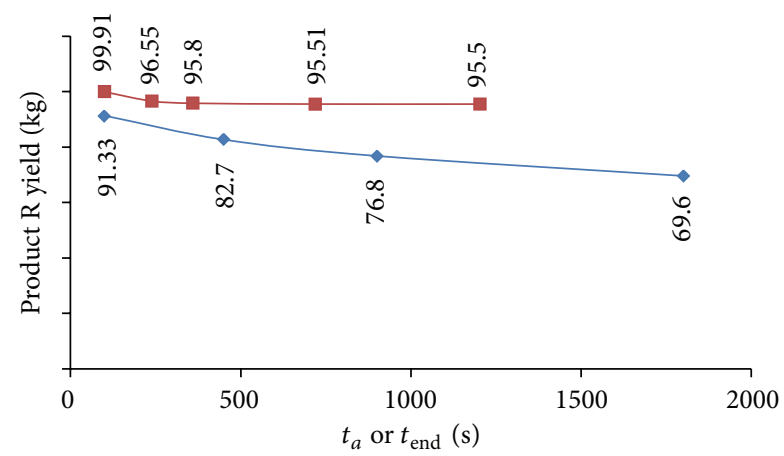

$\longrightarrow$ Fed-Batch Reactor

$\rightarrow$ Plug Flow Reactor

FIgURE 11: Product yield as a function of addition time and reaction end time in Fed Batch Reactor and Plug Flow Reactor, respectively (Scheme 8, Part 2).

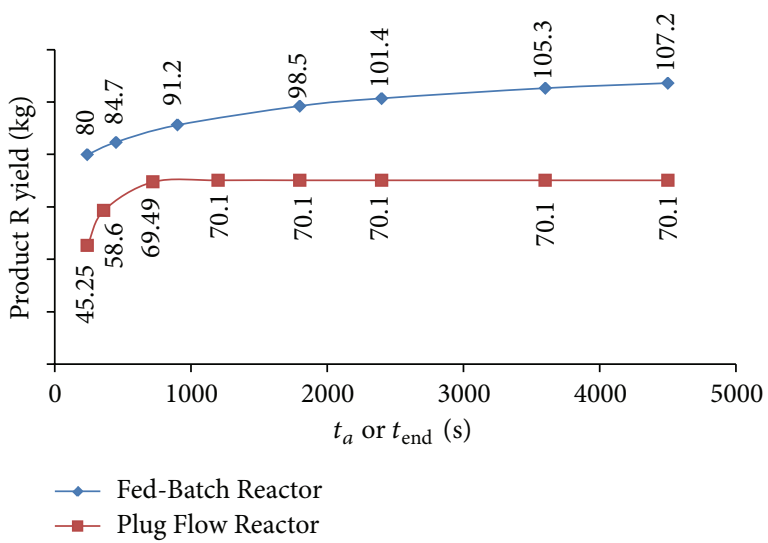

FIgURE 12: Product yield as a function of addition time and reaction end time in Fed Batch Reactor and Plug Flow Reactor respectively (Scheme 9, Part 2). 
Table 9: (a) Reactor-1 (Fed-Batch, Scheme 8, Part 1). (b) Reactor-2 (Plug Flow, Scheme 8, Part 1). (c) Reactor-1 (Fed-Batch, Scheme 8, Part 2). (d) Reactor-2 (Plug Flow, Scheme 8, Part 2). (e) Reactor-1 (Fed-Batch, Scheme 8, Part 3). (f) Reactor-2 (Plug Flow, Scheme 8, Part 3).

(a)

\begin{tabular}{lccccccc}
\hline$t_{a}(\mathrm{~s})$ & $N_{\mathrm{B} t} / N_{\mathrm{A} t}$ & $V_{t}\left(\mathrm{~m}^{3}\right)$ & $N_{\mathrm{AF}}(\mathrm{k} \mathrm{mol})$ & $N_{\mathrm{BF}}(\mathrm{k} \mathrm{mol})$ & $N_{\mathrm{RF}}(\mathrm{k} \mathrm{mol})$ & $N_{\mathrm{SF}}(\mathrm{k} \mathrm{mol})$ & $W_{\mathrm{R}}(\mathrm{kg})$ \\
\hline 60 & 1.76 & 2.144 & 0.027 & 0.00 & 0.588 & 2.052 & 27.5 \\
600 & 1.892 & 2.147 & 0.027 & 0.00 & 0.234 & 2.406 & 11.0 \\
\hline
\end{tabular}

(b)

\begin{tabular}{lccccccc}
\hline$t_{\text {end }}(\mathrm{s})$ & $N_{\mathrm{Bt}} / N_{\mathrm{A} t}$ & $V_{t}\left(\mathrm{~m}^{3}\right)$ & $N_{\mathrm{AF}}(\mathrm{k} \mathrm{mol})$ & $N_{\mathrm{BF}}(\mathrm{k} \mathrm{mol})$ & $N_{\mathrm{RF}}(\mathrm{k} \mathrm{mol})$ & $N_{\mathrm{SF}}(\mathrm{kmol})$ & $W_{\mathrm{R}}(\mathrm{kg})$ \\
\hline 6 & 1.216 & 2.13 & 0.027 & $3 E-26$ & 2.037 & 0.6 & 95.5 \\
60 & 1.216 & 2.13 & 0.027 & 0.000 & 2.037 & 0.6 & 95.5 \\
\hline
\end{tabular}

(c)

\begin{tabular}{lccccccc}
\hline$t_{a}(\mathrm{~s})$ & $N_{\mathrm{B} t} / N_{\mathrm{A} t}$ & $V_{t}\left(\mathrm{~m}^{3}\right)$ & $N_{\mathrm{AF}}(\mathrm{k} \mathrm{mol})$ & $N_{\mathrm{BF}}(\mathrm{k} \mathrm{mol})$ & $N_{\mathrm{RF}}(\mathrm{k} \mathrm{mol})$ & $N_{\mathrm{SF}}(\mathrm{k} \mathrm{mol})$ & $W_{\mathrm{R}}(\mathrm{kg})$ \\
\hline 450 & 1.318 & 2.133 & 0.027 & $6 E-06$ & 1.765 & 1.638 & 75 \\
900 & 1.366 & 2.124 & 0.027 & $9 E-06$ & 1.485 & 1.002 & 1.155 \\
1800 & 1.423 & 2.136 & 0.027 & $2 E-05$ & 1.656 & 0.984 & 76.8 \\
900 & 1.359 & 2.134 & 0.027 & $8 E-06$ & 1.615 & 1.025 \\
900 & 1.374 & 2.667 & 0.027 & $1 E-05$ & & 77.6 \\
\hline
\end{tabular}

(d)

\begin{tabular}{lccccccc}
\hline$t_{\text {end }}(\mathrm{s})$ & $N_{\mathrm{Bt}} / N_{\mathrm{A} t}$ & $V_{t}\left(\mathrm{~m}^{3}\right)$ & $N_{\mathrm{AF}}(\mathrm{k} \mathrm{mol})$ & $N_{\mathrm{BF}}(\mathrm{k} \mathrm{mol})$ & $N_{\mathrm{RF}}(\mathrm{k} \mathrm{mol})$ & $N_{\mathrm{SF}}(\mathrm{kmol})$ & $W_{\mathrm{R}}(\mathrm{kg})$ \\
\hline 240 & 1.218 & 2.13 & 0.027 & 0.029 & 2.06 & 0.58 & 96.55 \\
360 & 1.216 & 2.13 & 0.027 & 0.008 & 2.044 & 0.596 \\
720 & 1.216 & 2.13 & 0.027 & $2 E-04$ & 2.038 & 0.602 & 95.8 \\
240 & 1.218 & 2.13 & 0.027 & 0.029 & 2.06 & 0.58 & 96.51 \\
240 & 1.218 & 2.13 & 0.027 & 0.029 & 2.06 & 0.58 \\
\hline
\end{tabular}

(e)

\begin{tabular}{lccccccc}
\hline$t_{a}(\mathrm{~s})$ & $N_{\mathrm{B} t} / N_{\mathrm{A} t}$ & $V_{t}\left(\mathrm{~m}^{3}\right)$ & $N_{\mathrm{AF}}(\mathrm{k} \mathrm{mol})$ & $N_{\mathrm{BF}}(\mathrm{k} \mathrm{mol})$ & $N_{\mathrm{RF}}(\mathrm{k} \mathrm{mol})$ & $N_{\mathrm{SF}}(\mathrm{k} \mathrm{mol})$ & $W_{\mathrm{R}}(\mathrm{kg})$ \\
\hline 450 & 1.078 & 2.127 & 0.027 & 0.003 & 2.408 & 0.232 & 112.9 \\
900 & 1.09 & 2.127 & 0.027 & 0.002 & 2.376 & 0.264 & 111.4 \\
\hline
\end{tabular}

(f)

\begin{tabular}{lccccccc}
\hline$t_{\text {end }}(\mathrm{s})$ & $N_{\mathrm{B} t} / N_{\mathrm{A} t}$ & $V_{t}\left(\mathrm{~m}^{3}\right)$ & $N_{\mathrm{AF}}(\mathrm{k} \mathrm{mol})$ & $N_{\mathrm{BF}}(\mathrm{k} \mathrm{mol})$ & $N_{\mathrm{RF}}(\mathrm{k} \mathrm{mol})$ & $N_{\mathrm{SF}}(\mathrm{k} \mathrm{mol})$ & $W_{\mathrm{R}}(\mathrm{kg})$ \\
\hline 240 & 1.076 & 2.127 & 0.027 & 0.087 & 2.498 & 0.142 & 117.1 \\
360 & 1.065 & 2.127 & 0.027 & 0.046 & 2.486 & 0.154 & 116.6 \\
\hline
\end{tabular}

streams (Table 9(c), rows 2, 4, and 5). However, this variation is too low to catch up with Plug Flow Reactor yield.

10.6. (Scheme 9, $a=1.5, b=0.5, c=1$, and $d=1$, Nonelementary)

10.6.1. Part 1 (Cases 1 and 2) $K_{1}=100, K_{1} / K_{2}=10$, and $K_{2}=10$. See Tables 10(a) and 10(b).

10.6.2. Part 2 (Cases 1 to 5) $K_{1}=0.1, K_{1} / K_{2}=10$, and $K_{2}=$ 0.01 . The yield values for varying reaction times are captured in Figure 12.

In Tables $10(\mathrm{c})$ and $10(\mathrm{~d})$, the data lines (rows) 4 and 5 correspond to the fraction, Sol A/(Sol A + Sol R $)=0.25$ and 0.75 , respectively.
10.6.3. Part 3 (Cases 1 and 2) $K_{1}=0.1, K_{1} / K_{2}=50$, and $K_{2}=0.002$. Tables $10(\mathrm{a})-10(\mathrm{f})$ and Figure 12 show that this nonelementary reaction yields higher desired product in Fed-Batch Reactor than in Continuous Plug Flow Reactor.

As in Scheme 2 and Scheme 7, the Plug Flow Reactor yield initially increases with the increase in reaction time (i.e., lengthier reactor pipe); consequently, $N_{\mathrm{B} t} / N_{\mathrm{A} t}$ value decreases (i.e., reduced consumption of Reactant B). However, the Plug Flow Reactor yield saturates out below FedBatch Reactor yield (Figure 12).

Overall, the Fed Batch Reactor yields higher product $\mathrm{R}$ than Plug Flow Reactor, even though there is a very marginal change in yield for the change in the relative concentration of reacting streams (Table 10(c), rows 2, 4, and 5) in Fed-Batch Reactor. 
TABle 10: (a) Reactor-1 (Fed-Batch, Scheme 9, Part 1). (b) Reactor-2 (Plug Flow, Scheme 9, Part 1). (c) Reactor-1 (Fed-Batch, Scheme 9, Part 2). (d) Reactor-2 (Plug Flow, Scheme 9, Part 2). (e) Reactor-1 (Fed-Batch, Scheme 9, Part 3). (f) Reactor-2 (Plug Flow, Scheme 9, Part 3).

(a)

\begin{tabular}{lccccccc}
\hline$t_{a}(\mathrm{~s})$ & $N_{\mathrm{B} t} / N_{\mathrm{A} t}$ & $V_{t}\left(\mathrm{~m}^{3}\right)$ & $N_{\mathrm{AF}}(\mathrm{k} \mathrm{mol})$ & $N_{\mathrm{BF}}(\mathrm{k} \mathrm{mol})$ & $N_{\mathrm{RF}}(\mathrm{k} \mathrm{mol})$ & $N_{\mathrm{SF}}(\mathrm{k} \mathrm{mol})$ & $W_{\mathrm{R}}(\mathrm{kg})$ \\
\hline 60 & 1.019 & 2.125 & 0.027 & 0.00 & 2.564 & 0.077 & 120.2 \\
600 & 0.994 & 2.125 & 0.027 & 0.00 & 2.63 & $1 E-02$ & 123.3 \\
\hline
\end{tabular}

(b)

\begin{tabular}{lccccccc}
\hline$t_{\text {end }}(\mathrm{s})$ & $N_{\mathrm{Bt}} / N_{\mathrm{A} t}$ & $V_{t}\left(\mathrm{~m}^{3}\right)$ & $N_{\mathrm{AF}}(\mathrm{k} \mathrm{mol})$ & $N_{\mathrm{BF}}(\mathrm{k} \mathrm{mol})$ & $N_{\mathrm{RF}}(\mathrm{k} \mathrm{mol})$ & $N_{\mathrm{SF}}(\mathrm{kmol})$ & $W_{\mathrm{R}}(\mathrm{kg})$ \\
\hline 6 & 1.419 & 2.135 & 0.027 & $2 E-11$ & 1.497 & 1.1 & 70.15 \\
60 & 1.419 & 2.135 & 0.027 & $2 E-11$ & 1.497 & 1.1 & 70.15 \\
\hline
\end{tabular}

(c)

\begin{tabular}{lccccccc}
\hline$t_{a}(\mathrm{~s})$ & $N_{\mathrm{B} t} / N_{\mathrm{A} t}$ & $V_{t}\left(\mathrm{~m}^{3}\right)$ & $N_{\mathrm{AF}}(\mathrm{k} \mathrm{mol})$ & $N_{\mathrm{BF}}(\mathrm{k} \mathrm{mol})$ & $N_{\mathrm{RF}}(\mathrm{k} \mathrm{mol})$ & $N_{\mathrm{SF}}(\mathrm{k} \mathrm{mol})$ & $W_{\mathrm{R}}(\mathrm{kg})$ \\
\hline 450 & 1.302 & 2.133 & 0.027 & $4 E-15$ & 1.807 & 1.946 & 0.833 \\
900 & 1.25 & 2.131 & 0.027 & $4 E-15$ & 2.101 & 0.694 & 0.539 \\
1800 & 1.192 & 2.13 & 0.027 & $4 E-15$ & 1.936 & 0.704 & 98.2 \\
900 & 1.254 & 2.131 & 0.027 & $4 E-15$ & 1.957 & 90.7 \\
900 & 1.246 & 2.131 & 0.027 & $4 E-15$ & & 0.683 & 91.7 \\
\hline
\end{tabular}

(d)

\begin{tabular}{lccccccc}
\hline$t_{\text {end }}(\mathrm{s})$ & $N_{\mathrm{Bt}} / N_{\mathrm{A} t}$ & $V_{t}\left(\mathrm{~m}^{3}\right)$ & $N_{\mathrm{AF}}(\mathrm{k} \mathrm{mol})$ & $N_{\mathrm{BF}}(\mathrm{k} \mathrm{mol})$ & $N_{\mathrm{RF}}(\mathrm{k} \mathrm{mol})$ & $N_{\mathrm{SF}}(\mathrm{kmol})$ & $W_{\mathrm{R}}(\mathrm{kg})$ \\
\hline 240 & 1.771 & 2.144 & 0.027 & 0.408 & 0.965 & 1.675 & 45.25 \\
360 & 1.544 & 2.139 & 0.027 & 0.088 & 1.251 & 1.389 & 58.6 \\
720 & 1.425 & 2.136 & 0.027 & 0.001 & 0.965 & 1.158 & 1.675 \\
240 & 1.771 & 2.144 & 0.027 & 0.408 & 0.965 & 1.675 \\
240 & 1.771 & 2.144 & 0.027 & 0.408 & & 45.25 \\
\hline
\end{tabular}

(e)

\begin{tabular}{lccccccc}
\hline$t_{a}(\mathrm{~s})$ & $N_{\mathrm{B} t} / N_{\mathrm{A} t}$ & $V_{t}\left(\mathrm{~m}^{3}\right)$ & $N_{\mathrm{AF}}(\mathrm{k} \mathrm{mol})$ & $N_{\mathrm{BF}}(\mathrm{k} \mathrm{mol})$ & $N_{\mathrm{RF}}(\mathrm{k} \mathrm{mol})$ & $N_{\mathrm{SF}}(\mathrm{k} \mathrm{mol})$ & $W_{\mathrm{R}}(\mathrm{kg})$ \\
\hline 450 & 1.04 & 2.667 & 0.027 & $1 E-06$ & 2.506 & 0.134 & 117.5 \\
900 & 1.034 & 2.126 & 0.027 & $4 E-15$ & 2.523 & 0.117 & 118.3 \\
\hline
\end{tabular}

(f)

\begin{tabular}{lccccccc}
\hline$t_{\text {end }}(\mathrm{s})$ & $N_{\mathrm{Bt}} / N_{\mathrm{A} t}$ & $V_{t}\left(\mathrm{~m}^{3}\right)$ & $N_{\mathrm{AF}}(\mathrm{k} \mathrm{mol})$ & $N_{\mathrm{BF}}(\mathrm{k} \mathrm{mol})$ & $N_{\mathrm{RF}}(\mathrm{k} \mathrm{mol})$ & $N_{\mathrm{SF}}(\mathrm{k} \mathrm{mol})$ & $W_{\mathrm{R}}(\mathrm{kg})$ \\
\hline 240 & 1.4 & 2.135 & 0.027 & 0.624 & 2.17 & 0.47 & 101.7 \\
360 & 1.191 & 2.13 & 0.027 & 0.202 & 2.307 & 0.333 & 108.1 \\
\hline
\end{tabular}

TABLE 11: Summary of results.

\begin{tabular}{lcccccc}
\hline $\begin{array}{l}\text { Scheme } \\
\text { number }\end{array}$ & $a$ & $b$ & $c$ & $d$ & Favored reactor & $\begin{array}{c}\text { Relationship } \\
\text { between } a, b, c \text {, and } \\
d\end{array}$ \\
\hline 1 & 1 & 1 & 1 & 1 & Both equally & $a+c=b+d$ \\
2 & 1 & 1 & 1.5 & 0.5 & Fed-Batch Reactor & $a+c>b+d$ \\
3 & 1 & 1 & 0.5 & 1.5 & Plug Flow Reactor & $a+c<b+d$ \\
4 & 0.5 & 1.5 & 0.5 & 1.5 & Plug Flow Reactor & $a+c<b+d$ \\
5 & 1.5 & 0.5 & 0.5 & 1.5 & Both equally & $a+c=b+d$ \\
6 & 0.5 & 1.5 & 1.5 & 0.5 & Both equally & $a+c=b+d$ \\
7 & 1.5 & 0.5 & 1.5 & 0.5 & Fed-Batch Reactor & $a+c>b+d$ \\
8 & 0.5 & 1.5 & 1 & 1 & Plug Flow Reactor & $a+c<b+d$ \\
9 & 1.5 & 0.5 & 1 & 1 & Fed-Batch Reactor & $a+c>b+d$ \\
\hline
\end{tabular}

\section{Conclusion}

Under the simulated conditions, elementary Second order competitive consecutive reactions of the type mentioned in (1) yield the same amount of intermediate product, R, in both ideal fed batch and ideal Plug Flow Reactors, for a constant conversion (99\%) of limiting reactant, A. Yield and selectivity of the product depends only on $K_{1} / K_{2}$ in both the reactors.

However, of the 8 nonelementary scenarios simulated, three (Schemes 3, 4, and 8) favor Plug Flow Reactor and three other (Schemes 2, 7, and 9) favor Fed Batch Reactor. Two others (Schemes 5, and 6), like elementary reaction, yield the same in both Plug Flow Reactor and Fed batch reactor.

Among the schemes simulated previously (Schemes 1 to 9), the schemes giving increased yield, $R$, with reduced addition time in Fed batch reactor favor Plug Flow Reactor, and the schemes giving increased yield with increased addition 
time in fed batch reactor favor Fed batch reactor. This could well be a practical reckoner to screen the potential candidate among the simulated schemes for Plug Flow Reactor, even though this idea is only with respect to suitability of kinetic parameters.

The relationship between the exponents $a, b, c$, and $d$ and the favourable reactor found in the simulation, as shown in Table 11, is noteworthy.

\section{Nomenclature}

\begin{tabular}{|c|c|}
\hline$K_{1}:$ & $\begin{array}{l}\text { Rate constant of reaction between } \mathrm{A} \text { and } \\
\mathrm{B} \text {, in Litre } \cdot \mathrm{mol}^{-1} \cdot \mathrm{s}^{-1}\end{array}$ \\
\hline$K_{2}:$ & $\begin{array}{l}\text { Rate constant of } 2 \text { nd reaction between } \mathrm{R} \\
\text { and } \mathrm{B} \text {, in Litre } \mathrm{mol}^{-1} \cdot \mathrm{s}^{-1}\end{array}$ \\
\hline$t:$ & Time, s \\
\hline$t_{a}:$ & $\begin{array}{l}\text { Reactant B addition time in Fed Batch } \\
\text { Reactor, } s\end{array}$ \\
\hline$t_{m}:$ & $\begin{array}{l}\text { Reaction mass maintenance time in Fed } \\
\text { Batch Reactor, } s\end{array}$ \\
\hline$t^{*}:$ & Space time in Plug Flow Reactor, s \\
\hline$t_{\text {end }}:$ & $\begin{array}{l}\text { Space time, for which each case of plug } \\
\text { flow rector simulation has been done, } s\end{array}$ \\
\hline$r_{x}:$ & $\begin{array}{l}\text { Rate of change of species " } x \text { " } \\
\left(\text { mol.Litre }{ }^{-1} \cdot s^{-1}\right) \text { " } x \text { " is representative of } \\
\text { species } A, B, R, S, C \text {, and D }\end{array}$ \\
\hline$C_{x}=N_{x} / V$ & $\begin{array}{l}\text { Concentration, } \mathrm{mol} \cdot \text { Litre }^{-1} \text {, of any species, } \\
\text { say, " } x \text { " }\end{array}$ \\
\hline$V:$ & Reaction volume, $\mathrm{m}^{3}$ \\
\hline$N_{x}:$ & Number of Kg moles of species “ $x$ ”, $\mathrm{k}$ mol \\
\hline$N_{\mathrm{B} t}:$ & $\begin{array}{l}\text { Total Kg moles of reactant B used in } \\
\text { reaction, } \mathrm{k} \mathrm{mol}\end{array}$ \\
\hline$N_{\mathrm{A} t}:$ & $\begin{array}{l}\text { Total kg moles of reactant } \mathrm{A} \text { used in } \\
\text { reaction, } \mathrm{k} \mathrm{mol}\end{array}$ \\
\hline$V_{a t}:$ & $\begin{array}{l}\text { Volume of stream containing reactant } B, \\
\mathrm{~m}^{3}\end{array}$ \\
\hline$V_{t}:$ & $\begin{array}{l}\text { Total volume of contents including } \\
\text { streams of reactant A and reactant } \mathrm{B}, \mathrm{m}^{3}\end{array}$ \\
\hline$v:$ & Plug Flow Reactor volume, $\mathrm{m}^{3}$ \\
\hline$v^{\prime}:$ & Volumetric flow rate, $\mathrm{m}^{3} / \mathrm{s}$ \\
\hline$F_{x}:$ & $\begin{array}{l}\text { Molar flow rate }\left(\mathrm{k} \mathrm{mol} \cdot \mathrm{s}^{-1}\right) \text { of species " } x \text { ", } \\
\text { which is representative of species A, B, R, } \\
\mathrm{S}, \mathrm{C} \text {, and D }\end{array}$ \\
\hline$N_{\mathrm{B} t} / N_{\mathrm{A} t}:$ & $\begin{array}{l}\text { Ratio of total moles of B to total moles of } \\
\text { A taken for the reaction }\end{array}$ \\
\hline$N_{x F}:$ & Final kg moles of the species “ $x$ ”, k mol \\
\hline$W_{\mathrm{R}}:$ & $\begin{array}{l}\text { Weight, } \mathrm{kg} \text {, of total intermediate (desired) } \\
\text { product formed at the end of reaction in } \\
\text { Fed Batch Reactor and at the end of a } \\
\text { given space time in the Plug Flow Reactor. }\end{array}$ \\
\hline
\end{tabular}

\section{Acknowledgment}

The author would like to thank Chandra Kanth Terupally of Planck Technical, Hyderabad, India, for providing adequate support in MATLAB Programming.

\section{References}

[1] O. Levenspiel, Chemical Reaction Engineering, John Wiley \& Sons, New York, NY, USA, 3rd edition, 1998.

[2] J. F. Richardson and D. G. Peacock, Coulson and Richardson's Chemical Engineering: Chemical and Biochemical Reactors and Process Control, Butterworth-Heinemann, Boston, Mass, USA, 3rd edition, 1994.

[3] S. I. A. Shah, L. W. Kostiuk, and S. M. Kresta, "The effects of mixing, reaction rates, and stoichiometry on yield for mixing sensitive reactions-part I: model development," International Journal of Chemical Engineering, vol. 2012, Article ID 750162, 16 pages, 2012.

[4] S. I. A. Shah, L. W. Kostiuk, and S. M. Kresta, "The effects of mixing, reaction rates, and stoichiometry on yield for mixing sensitive reactions-part II: design protocols," International Journal of Chemical Engineering, vol. 2012, Article ID 654321, 13 pages, 2012.

[5] J. R. Bourne, "Mixing and the selectivity of chemical reactions," Organic Process Research and Development, vol. 7, no. 4, pp. 471508, 2003.

[6] J. Bałdyga, J. R. Bourne, and S. J. Hearn, "Interaction between chemical reactions and mixing on various scales," Chemical Engineering Science, vol. 52, no. 4, pp. 457-466, 1997.

[7] N. G. Anderson, "Practical use of continuous processing in developing and scaling up laboratory processes," Organic Process Research and Development, vol. 5, no. 6, pp. 613-621, 2001.

[8] C. Brechtelsbauer and F. Ricard, "Reaction engineering evaluation and utilization of static mixer technology for the synthesis of pharmaceuticals," Organic Process Research and Development, vol. 5, no. 6, pp. 646-651, 2001.

[9] Z. Anxionnaz, M. Cabassud, C. Gourdon, and P. Tochon, "Heat exchanger/reactors (HEX reactors): concepts, technologies: state-of-the-art," Chemical Engineering and Processing, vol. 47, no. 12, pp. 2029-2050, 2008.

[10] P. Barthe, C. Guermeur, O. Lobet et al., "Continuous multiinjection reactor for multipurpose production-part I," Chemical Engineering and Technology, vol. 31, no. 8, pp. 1146-1154, 2008.

[11] M. Patel and G. Gasparini, "Reactor technology: flow reactors and dynamic mixing," Specialty Chemicals Magazine, 2009.

[12] X. W. Ni, "Continuous oscilatory baffled reactor technology," in Innovations in Pharmaceutical Technology-Manufacturing, pp. 90-96, 2006, http://www.iptonline.com/pdf_viewarticle. asp? cat $=5 \&$ article $=392$.

[13] L. Proctor, "Continuous chemical processing," in Innovations in Pharmaceutical Technology, pp. 84-88, http://www.iptonline. $\mathrm{com} /$ pdf_viewarticle.asp?cat $=5 \&$ article $=290$. 

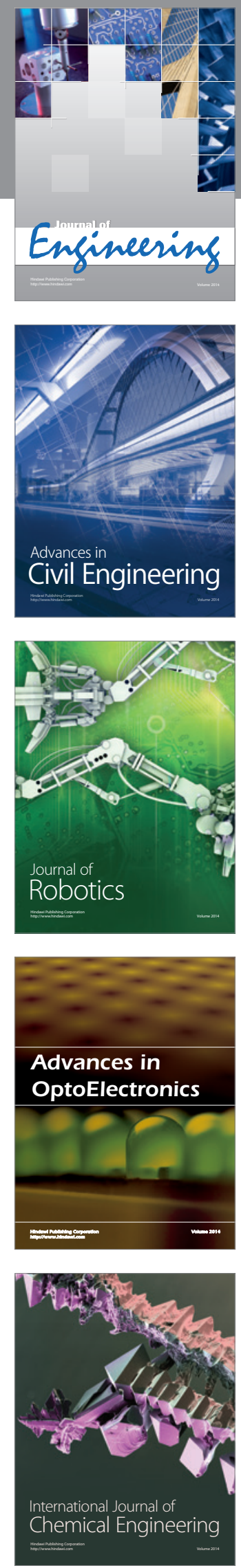

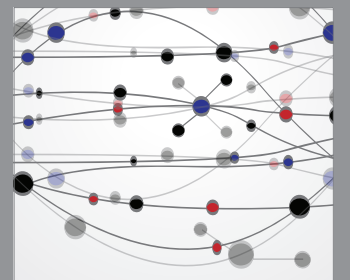

The Scientific World Journal
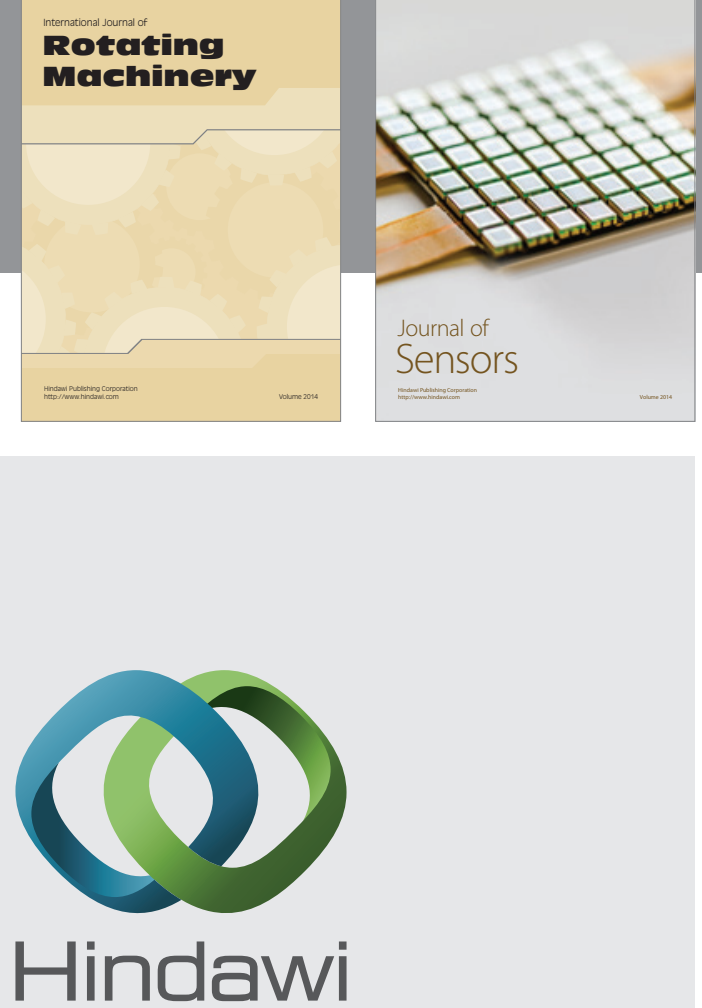

Submit your manuscripts at http://www.hindawi.com
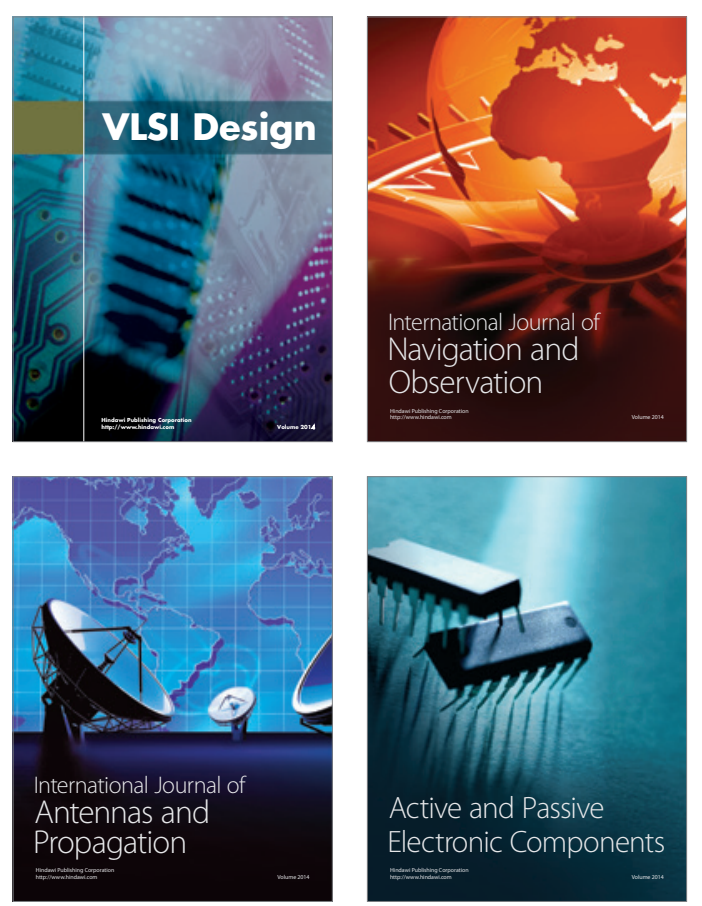
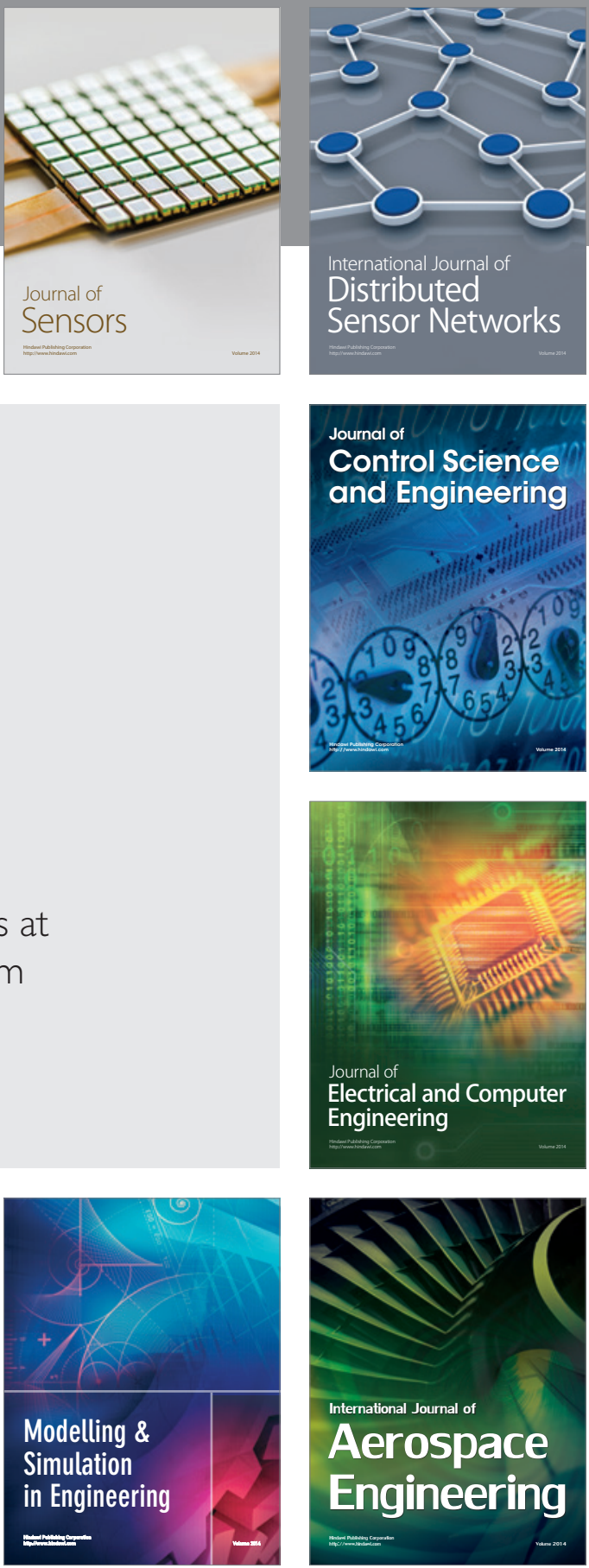

Journal of

Control Science

and Engineering
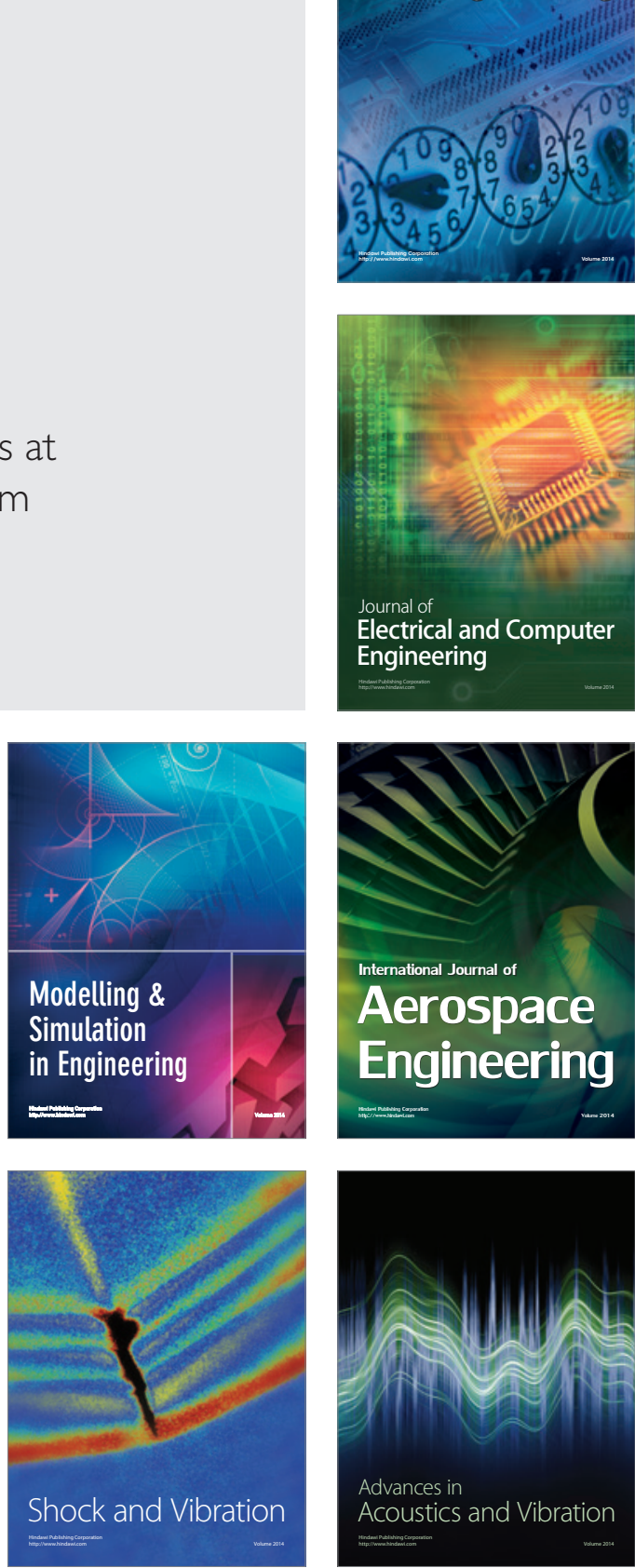